NATIONAL LABORATORY

MANAGED BY UT-BATTELLE

FOR THE DEPARTMENT OF ENERGY

\title{
RSAP - A Code for Display of Neutron Cross Section Data and SAMMY Fit Results
}

February 2001

R. O. SAYER

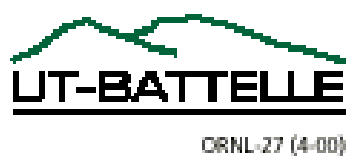




\section{DOCUMENT AVAILABILITY}

Reports produced after January 1, 1996, are generally available free via the U.S. Department of Energy (DOE) Information Bridge:

Web site: http://www.osti.gov/bridge

Reports produced before January 1, 1996, may be purchased by members of the public from the following source:

National Technical Information Service

5285 Port Royal Road

Springfield, VA 22161

Telephone: 703-605-6000 (1-800-553-6847)

TDD: 703-487-4639

Fax: 703-605-6900

E-mail: info@ntis.fedworld.gov

Web site: http://www.ntis.gov/support/ordernowabout.htm

Reports are available to DOE employees, DOE contractors, Energy Technology Data Exchange (ETDE) representatives, and International Nuclear Information System (INIS) representatives from the following source:

Office of Scientific and Technical Information

P.O. Box 62

Oak Ridge, TN 37831

Telephone: 865-576-8401

Fax: 865-576-5728

E-mail: reports@adonis.osti.gov

Web site: http://www.osti.gov/contact.html

This report was prepared as an account of work sponsored by an agency of the United States Government. Neither the United States government nor any agency thereof, nor any of their employees, makes any warranty, express or implied, or assumes any legal liability or responsibility for the accuracy, completeness, or usefulness of any information, apparatus, product, or process disclosed, or represents that its use would not infringe privately owned rights. Reference herein to any specific commercial product, process, or service by trade name, trademark, manufacturer, or otherwise, does not necessarily constitute or imply its endorsement, recommendation, or favoring by the United States Government or any agency thereof. The views and opinions of authors expressed herein do not necessarily state or reflect those of the United States Government or any agency thereof. 
ORNL/TM-2001/15

Computational Physics and Engineering Division

\title{
RSAP - A Code for Display of Neutron Cross Section Data and SAMMY Fit Results
}

\author{
R. O. Sayer
}

Date Published: February 2001

\author{
Prepared by \\ OAK RIDGE NATIONAL LABORATORY \\ P.O. Box 2008 \\ Oak Ridge, Tennessee 37831-6285 \\ managed by \\ UT-Battelle, LLC \\ for the \\ U.S. DEPARTMENT OF ENERGY \\ under contract DE-AC05-00OR22725
}





\section{CONTENTS}

LIST OF FIGURES …............................................................................. iv

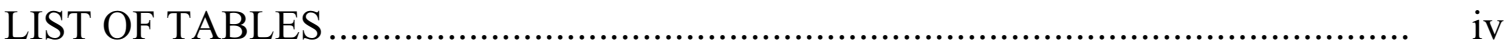

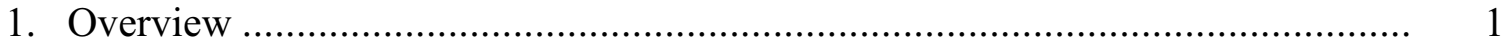

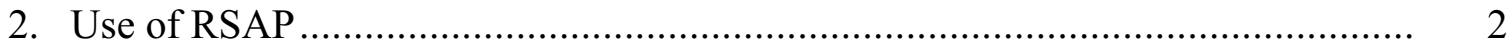

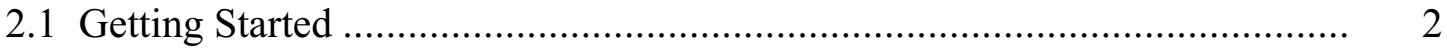

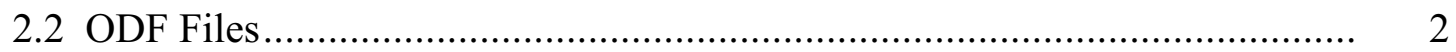

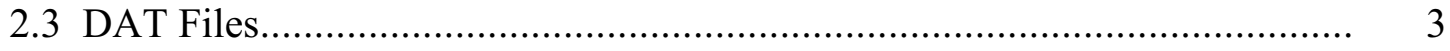

2.4 Multiple Plots in a Window ................................................................. 3

2.5 Overlay of 2 or more Plots ..................................................................... 4

2.6 Plot File Formats ........................................................................ 4

3. RSAP Specifiers and Plot Requests .................................................... 5

Table 1. RSAP Plot Types ................................................................... 5

Table 2. RSAP Specifiers and Arguments..................................................... 6

4. Example Input Files ............................................................................... 8

5. Peak Search and Fitting ......................................................................... 26

6. Automatic Spin Group Variation ......................................................... 29

6.1 Resonances treated sequentially........................................................ 32

6.2 Two Resonances treated simultaneously .............................................. 32

ACKNOWLEDGEMENTS ..................................................................... 35

REFERENCES …............................................................................... 35

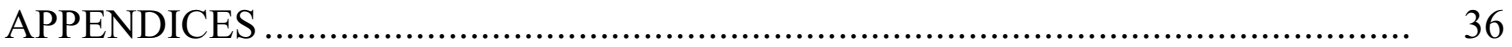
A. Example Script for SAMMY + RSAP Run ......................................... 36
B. Example rsap.ratexpth File ................................................................ 36
C. Example rsap.parcom File................................................................. 37
D. PLPLOT Metafiles and plrender...................................................... 38 


\section{LIST OF FIGURES}

Figure

1 /home/ros/axp/RSAP/EXAMPLE/1/inx

2 /home/ros/axp/RSAP/EXAMPLE/2/inx

3 /home/ros/axp/RSAP/EXAMPLE/3/inxs2

4 /home/ros/axp/RSAP/EXAMPLE/4/alortrantot

5 /home/ros/axp/RSAP/EXAMPLE/5/incolxpsc

6 /home/ros/axp/RSAP/EXAMPLE/6/incap

7 /home/ros/axp/RSAP/EXAMPLE/7/in3odf

8 /home/ros/axp/RSAP/EXAMPLE/8/inpl_231

9 /home/ros/axp/RSAP/EXAMPLE/9/inovr6

10 /home/ros/axp/RSAP/EXAMPLE/10/intxt

11 /home/ros/axp/RSAP/EXAMPLE/11/transxps

12 /home/ros/axp/RSAP/EXAMPLE/12/dosgv25 Automatic Spin Group Vary
Page

One Plot in 1 Window ......... 9

Stack 2 frames in 1 Window $\quad 10$

Plot from 2 ODF Files........ 11

13

16

17

19

21

23

25

27

30

\section{LIST OF TABLES}

\section{Table}

Page

2 RSAP Specifiers and Arguments. 


\title{
RSAP - A Code for Display of Neutron Cross Section Data and SAMMY Fit Results
}

\author{
R. O. Sayer
}

\section{Overview}

RSAP is a computer code for display of neutron cross section data and selected SAMMY output. SAMMY [1] is a multilevel R-matrix code for fitting neutron time-offlight cross-section data using Bayes' method. RSAP, which runs on the Digital Unix Alpha platform, reads ORELA Data Files (ODF) created by SAMMY and uses graphics routines from the PLPLOT [2] package. In addition, RSAP can read data and/or computed values from ASCII files with a format specified by the user.

Plot output may be displayed in an X window, sent to a postscript file (rsap.ps), or sent to a color postscript file (rsap.psc). Thirteen plot types are supported, allowing the user to display cross section data, transmission data, errors, theory, "Bayes" fits, and residuals in various combinations. In this document the designations "theory" and "Bayes" refer to the initial and final theoretical cross sections, respectively, as evaluated by SAMMY. Special plot types include Bayes/Data, Theory - Data, and Bayes - Data. Output from two SAMMY runs may be compared by plotting the ratios Theory $2 /$ Theory 1 and Bayes2/Bayes 1 or by plotting the differences (Theory2 - Theory1) and (Bayes2 - Bayes1).

The term "plot" is used to denote a graphical representation of a combination of data, theory, errors, and Bayes from one ODF file. Several plots may be stacked in a single frame in a window (or page) with a common x-axis. RSAP also supports multiple frames in a window with each frame containing a separate plot. Up to 8 plots may be superposed, or overlaid, in one window with a separate normalization factor applied to each data set. The term "data set" denotes the numerical values of data, theory, etc. in one ODF file.

Data may be plotted as histograms, points, small circles, or large circles. Theoretical values may be displayed as solid or dashed lines. Each axis may be linear or logarithmic. Any one of the colors red, blue, green, cyan, yellow, magenta, or white may be specified for data, theory, Bayes, axes, and text. For example, the specifier:

\section{$\operatorname{col}$ y $r \mathrm{~g}$}

indicates colors yellow for theory, red for Bayes, and green for data. These are the defaults. Note that white ("w") shows well on the screen and in postscript plots, but white is invisible in color postscript plots. A detailed example is presented in section 4.5.

Plots may be annotated in several ways:

- values of resonance energies and widths read from a user-specified "PAR" file.

- user-specified X- and Y-axis label strings.

- User-specified annotation strings may be written at user-specified locations.

- A title string may be written above the plot. 
Two text fonts, Simple and Roman, are supported. The default Simple font draws faster on the screen, and the Roman font is more readable for hard copy and publication quality plots.

RSAP produces an ASCII file "rsap.parcom" containing a formatted comparison of the user-specified PAR file with the file "SAMMY.PAR" and an ASCII file "rsap.ratexpth" in which energies, data, errors, theory, results of a SAMMY Bayes run, and percentage differences are listed. If SAMMY.LPT exists, the final value of the conventional CHISQ/N will be written on the plot.

RSAP reads input from either the keyboard or a file, and produces plots as specified by input quantities. To run RSAP on a DEC Alpha machine in the ORNL CAD farm:

or

rsap

rsap < inputfile

where "inputfile" is the name of your input file. Sample RSAP input files are listed and explained in section 4, Example Input Files. Each example corresponds to one of the sample plots displayed in Figures 1-10.

The following sections include discussion of RSAP usage, plot types, RSAP specifiers, example input files, peak search and fitting, and automatic spin group variation.

\section{Use of RSAP}

This section provides a brief introduction to some of the features of RSAP as well as descriptions of input data files and output plot file formats. More detail is given in sections 3-6.

\subsection{Getting Started}

A good place to begin is Example 1, which plots data, errors, and the Bayes fit in one frame. Read the documentation in section 4 and run this simple case. Then copy the input file to your directory, and try different options, types of plots, etc. Try one of your ODF files. Run example 2 to stack two frames in one window and example 3 to plot from two ODF files. All example cases may be run sequentially with the script:

/home/ros/axp/RSAP/v5/EXAMPLE/doexamples

Typing " $h$ " at the RSAP prompt will list plot types and specifiers.

\subsection{ODF Files}

RSAP reads ORELA Data Files (ODF) created by SAMMY runs on Digital Unix Alpha workstations. A maximum of 60000 data points is allowed. Data points may be averaged before plotting by using the avg specifier. 
All ODF files in the user's current directory may be opened by following the odf specifier with a space and asterisk e.g., "odf $*$ ".

SAMMY writes ODF files with energies in units of $\mathrm{eV}(\mathrm{keV})$ if the maximum energy is less (greater) than $1 \mathrm{keV}$. The ODF file structure does not include information on energy units. Thus, the user must specify the energy units, either by the default $(\mathrm{keV})$, or by selecting eV with the specifier "ev 2 ".

\subsection{DAT Files}

RSAP can read data and/or computed values from an ASCII "DAT" file with a userspecified format. Five quantities are read per record: $\mathrm{x}, \mathrm{y} 1$, err1, y2, and $\mathrm{y} 3$. These quantities can be any set of numerical data; however, in order to use the same RSAP commands as those used for ODF files, the code makes the correspondences $\mathrm{x} \Leftrightarrow$ energy, $\mathrm{y} 1 \Leftrightarrow$ data, err $1 \Leftrightarrow$ error, $\mathrm{y} 2 \Leftrightarrow$ theory, and $\mathrm{y} 3 \Leftrightarrow$ Bayes. Note that the initial and final theoretical cross sections evaluated by SAMMY are denoted by the terms "theory" and "Bayes", respectively. Thus the RSAP plot request "1 dt" will plot y1 (data) and y2 (theory) vs. x (energy). The user may specify axes labels pertaining to the actual information in the DAT file; for example

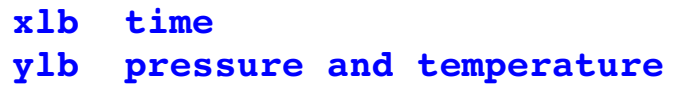

The default format is (5e11), corresponding to the csisrs data format. Other formats are selected with the fmt specifier; for example fmt (5e20.6). A maximum of 60000 data records is allowed. Data points may be averaged before plotting by using the avg specifier.

\subsection{Multiple Plots in a Window}

Multiple plots in a window may be accomplished by specifying more than 1 frame in either the $\mathrm{x}$ - or the $\mathrm{y}$-direction through the "ops" command. Each frame will contain a plot with unique $\mathrm{x}$ - and y-axes. For example, use "ops 23 " to plot 6 data sets in a 2 x 3 matrix in $\mathrm{x}$ and $\mathrm{y}$.
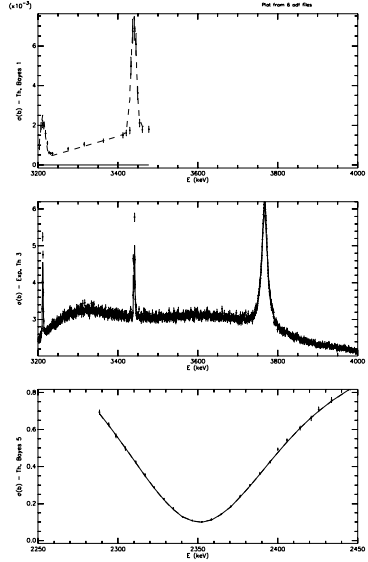
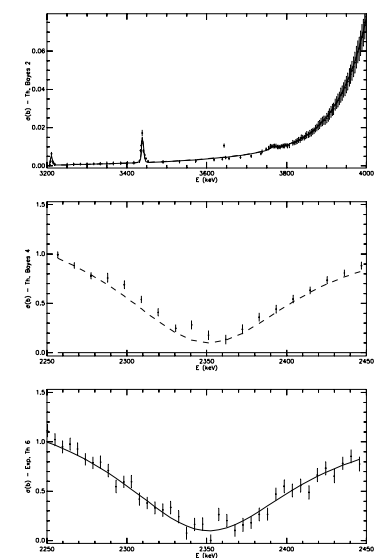
Two to eight plots may be "stacked" in the same frame using a common x-axis. A given plot may include any combination of data, theory, and Bayes values. Examples 2 and 3 illustrate the use of the "ops 11 2" command to stack 2 plots in one frame (see Figures 2 and 3). To plot 8 data sets, stacking 4 plots per frame in a $2 \times 1$ matrix in $\mathrm{x}$ and y:

ops $\quad \begin{array}{lll}2 & 1 & 4\end{array}$
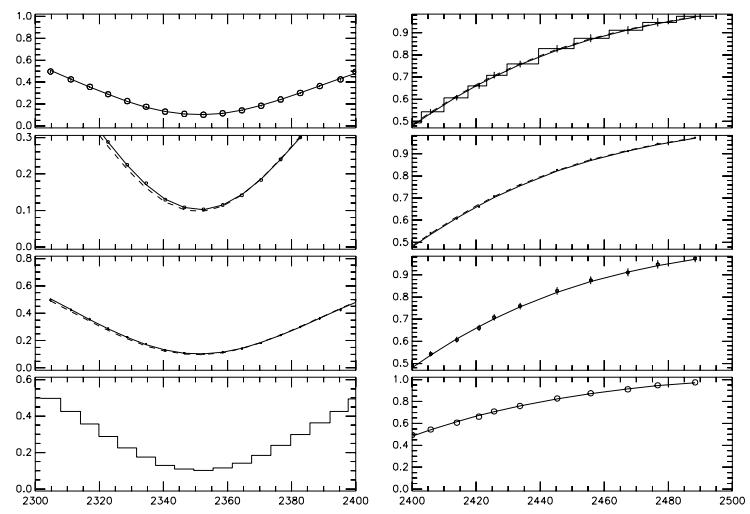

\subsection{Overlay of 2 or more Plots}

RSAP allows up to 8 "plots" to be overlaid in the same frame using common $\mathrm{x}$ - and $\mathrm{y}$ axes. A particular plot may include any combination of data, theory, and Bayes values. A normalization factor may be applied to each data set via the "nrm" specifier as defined in section 3. This overlay feature is most useful for showing general features of fits to several data sets. Example 9 illustrates the use of normalization factors in an overlay.

\subsection{Plot File Formats}

The color (monochrome) postscript file rsap.psc (rsap.ps) produced by RSAP may be converted to GIF, JPEG, or TIFF format with the $\mathbf{x v}$ program. For example, the command

$$
\text { xv -rot } 90 \text {-cmap rsap.psc }
$$

displays both rsap.psc and the xv control window. Click on "SAVE" in the control window and choose the file format in the "SAVE" window.

RSAP also produces a PLPLOT metafile, rsap.meta, that may be rendered with the plrender procedure described in Appendix D. For example, to make a color postscript file, rsap_port, in portrait orientation:

plrender -dev psc -o rsap_port -ori 3 rsap.meta 


\section{RSAP Specifiers and Plot Requests}

RSAP input consists of "specifier" cards and plot request cards. At least one "odf" or "dat" specifier is required to define an input file. Other specifiers such as "ops" may be included to set various input parameters. A device specifier (x, ps, or psc) is required to set the output device to (X-window, postscript file, or color postscript file).

Note that the device specifier " $\mathrm{x}$ " sends the plot to an X plot window, the color postscript file rsap.psc, the monochrome postscript file rsap.ps, and the PLPLOT metafile rsap.meta. Specifiers ps and psc send output to postscript files only.

After a device specifier, RSAP expects one or more plot request cards. Plot request input consists of the ODF file number, plot type, emin, emax, ymin, ymax in (a2, a4, 4f10) format. X- and Y-axis limits are denoted by (emin, emax) and (ymin, ymax), respectively. Axes limits default to the data limits. RSAP plot types and specifiers are listed in Tables 1 and 2 , respectively.

Table 1. RSAP Plot Types

\begin{tabular}{||l|l||}
\hline TYPE & DESCRIPTION \\
\hline 1 d & CROSS SECTION Data from ODF file 1 \\
\hline 2 d & CROSS SECTION Data from ODF file 2 \\
\hline 1 de & Data, Errors \\
\hline 1 dt & Data, Theory (INITIAL theoretical cross section) \\
\hline 1 db & Data, Bayes (FINAL theoretical cross section) \\
\hline 1 det & Data, Errors, Theory \\
\hline 1 deb & Data, Errors, Bayes \\
\hline 1 rt & Residuals, Theory \\
\hline 1 rb & Residuals, Bayes \\
\hline 1 bod & Bayes/Data \\
\hline 1 dtb & Data, Theory, Bayes \\
\hline 1 etb & Data, Errors, Theory, Bayes \\
\hline 1 tmd & Theory - Data \\
\hline 1 bmd & Bayes - Data \\
\hline & \\
\hline a d & TRANSMISSION Data from ODF file 1 \\
\hline b d & TRANSMISSION Data from ODF file 2 \\
\hline a de & TRANSMISSION Data, Errors \\
\hline a dt & Data, Theory \\
\hline$\ldots$ & ... \\
\hline 12 tot & (Theory from file 2) / (Theory from file 1) \\
\hline $12 \mathrm{bob}$ & (Bayes from file 2) / (Bayes from file 1) \\
\hline $12 \mathrm{tmt}$ & Theory2 - Theory1 \\
\hline $12 \mathrm{bmb}$ & Bayes2 - Bayes1 \\
\hline & \\
\hline
\end{tabular}


Table 2. RSAP Specifiers and Arguments

\begin{tabular}{|c|c|c|c|}
\hline SPECIFIER & ARGUMENTS & FORMAT & $\begin{array}{l}\text { DESCRIPTION } \\
\text { example }\end{array}$ \\
\hline ann & $\begin{array}{l}\text { kpl, } \\
\text { ka, } \\
\text { kacol } \\
\text { ann_string }\end{array}$ & $\begin{array}{l}\text { i1, } \\
\text { i1, } \\
\text { i2 } \\
\text { a40 }\end{array}$ & $\begin{array}{l}\text { Plot \# for this string } \\
1,2,3 \text { for left, center, right above frame top } \\
4,5,6 \text { for left, center, right below frame top } \\
\text { color } \\
\text { annotation string } \\
\text { ann } 14 \text { This is an annotation }\end{array}$ \\
\hline avg & kaverage & i2 & $\begin{array}{l}\text { \# of data points to average before plotting } \\
\text { avg } 12\end{array}$ \\
\hline bug & kdebug & i2 & $>0$ says print debug information \\
\hline cap & capt_string & a64 & $\begin{array}{l}\text { Caption string - up to } 64 \text { characters } \\
\text { cap This is a caption }\end{array}$ \\
\hline $\mathbf{c m f}$ & cmf_name & a72 & Command file name - up to 72 characters \\
\hline col & kt,kb,kd,ka,kt & $5 \mathbf{a} 2$ & $\begin{array}{l}\text { colors for theory,Bayes,data,axes,text } \\
\text { one of "y","r","g","c","b","m","w" } \\
\text { col y r b }\end{array}$ \\
\hline dat & dat_name & a72 & $\begin{array}{l}\text { DAT file name - up to } 72 \text { characters } \\
\text { dat / home/xyz/u235/mydata }\end{array}$ \\
\hline ev & kplev & i2 & $\begin{array}{l}=2 \text { says } \mathrm{ODF} \text { energies are in } \mathrm{eV} \\
>0 \text { says resonance energies, widths in } \mathrm{eV} \\
\mathrm{ev} \quad 2\end{array}$ \\
\hline fmt & fmt_string & a72 & $\begin{array}{l}\text { format string for dat files } \\
\text { fmt }(5 e 20.4)\end{array}$ \\
\hline fnt & kfont & i2 & $\begin{array}{l}1 \text { (2) says SIMPLE (ROMAN) font } \\
\text { fnt } 2\end{array}$ \\
\hline $\mathbf{h}$ & & & prints "help" messages \\
\hline lab & kodf, kdate, kchi & $3 \mathbf{i} 2$ & $\begin{array}{l}=0: \text { don't write odf name, date, chisq/n } \\
1 \mathrm{ab} \quad 0 \quad 0 \quad 0\end{array}$ \\
\hline $\log$ & kx, ky & $2 \mathrm{i} 2$ & $\begin{array}{l}\text { kx }(\mathbf{k y})>0 \text { says logarithmic } x(y) \text { axis } \\
\log 01\end{array}$ \\
\hline lpr & & & sends rsap.ps to default printer \\
\hline nrm & $\operatorname{Anorm}(1-8)$ & $8 f$ & $\begin{array}{l}\text { Normalize ODF File i by Anorm(i) } \\
\mathrm{nrm} \quad 1.0,2.4,0.76,8.25\end{array}$ \\
\hline odf & $\begin{array}{l}\text { Odfname } \\
*\end{array}$ & $\begin{array}{l}\text { a72 } \\
\text { a1 }\end{array}$ & $\begin{array}{l}\text { ODF file name - up to } 72 \text { characters } \\
\text { Reads up to } 8 \text { ODF files in current directory } \\
\text { odf } / \text { home } / x y z / u 235 / \text { total odf }\end{array}$ \\
\hline ops & $\begin{array}{l}\text { nx,ny,kstack, } \\
\text { kpts, } \\
\text { keres,kgamr }\end{array}$ & $6 \mathbf{i 2}$ & $\begin{array}{l}\text { \# } \mathbf{x} \text { frames, \# } \mathbf{y} \text { frames, \# plots stacked, } \\
0=\text { histogram, } 1=\text { dots, } 20(21)=\text { small(big) circles } \\
>\text { o says write res. Energies, Widths } \\
\text { ops } \begin{array}{llllllll}1 & 1 & 2 & 1 & 1 & 1\end{array}\end{array}$ \\
\hline ovr & kover & i2 & $\begin{array}{l}\text { Overlay kover plots in } 1 \text { window }(\text { kover }<9) \\
\text { ovr } 2\end{array}$ \\
\hline oxp & oxp_string & a72 & $\begin{array}{l}\text { String for plot request specifier } \\
\text { Default: oxp } 1 \mathrm{dtb}\end{array}$ \\
\hline
\end{tabular}


Table 2, RSAP Specifiers and Arguments, cont.

\begin{tabular}{|c|c|c|c|}
\hline SPECIFIER & ARGUMENTS & FORMAT & $\begin{array}{l}\text { DESCRIPTION } \\
\text { example }\end{array}$ \\
\hline par & inparfile & a72 & $\begin{array}{l}\text { PAR file name - up to } 72 \text { characters } \\
\text { par my_par_file_name }\end{array}$ \\
\hline pks & $\begin{array}{c}\text { fwhm, bias, a2targ, } \\
\text { Itarg, Jtot, gamgam, fwhmax }\end{array}$ & $7 f$ & $\begin{array}{l}\text { see section on Peak Search and Fitting } \\
\text { pks } 1.1,3.0,235 ., 0 ., 0.5,0.5,1.2\end{array}$ \\
\hline $\mathbf{q}$ & & & tells RSAP to quit. \\
\hline rat & kratout & i2 & > 0 says write values to file "rsap.ratexpth" \\
\hline sam & & & run SAMMY using PAR file rsap.peaks \\
\hline sgi & sgi_name & a72 & $\begin{array}{l}\text { SAMMY input file name - up to } 72 \text { characters } \\
\text { sgi my_SAMMY_input_file_name }\end{array}$ \\
\hline sgd & sgd_name & a72 & $\begin{array}{l}\text { SAMMY data file name - up to } 72 \text { characters } \\
\text { sgd my_SAMMY_data_file_name }\end{array}$ \\
\hline sgr & numres, jsg1, ..., jsg8 & $9 \mathrm{i} 4$ & $\begin{array}{l}\text { SGV resonance number, spin group list } \\
\text { sgr } 25,4,5,6\end{array}$ \\
\hline sgv & esglo, esghi & $2 f 8$ & $\begin{array}{l}\text { min and max energies for SGV fit } \\
\text { sgv } 380,430\end{array}$ \\
\hline sgp & & & Automatic plot of SGV fit results \\
\hline sym & $\operatorname{ksymodf}(1-8)$ & $8 i 4$ & $\begin{array}{l}\text { ksymodf(i) = symbol for ODF file } \mathbf{i} \\
\text { sym } 1,20,21,0,22\end{array}$ \\
\hline sys & command & a72 & $\begin{array}{l}\text { execute Unix "command" } \\
\text { sys mv oldname newname }\end{array}$ \\
\hline tit & title_string & a32 & $\begin{array}{l}\text { 32-character title string } \\
\text { tit my plot title }\end{array}$ \\
\hline txt & $\begin{array}{l}\text { kt, ktcol, } \\
\text { xt,yt, sizet, angle, } \\
\text { txtstring }\end{array}$ & $\begin{array}{l}2 \mathrm{i} 4 \\
4 \mathrm{f8.1} \\
\mathrm{a} 40\end{array}$ & $\begin{array}{l}\text { Odf \#, text color, } \\
\text { position }(x t, y t) \text {, size, angle, } \\
\text { 40-character text string } \\
\text { txt } 1,9,250.3,200,2.0, \text {, MyText }\end{array}$ \\
\hline xlb & xaxlabel & $\mathbf{a 2 4}$ & $\begin{array}{l}\text { 24-character } X \text {-axis label } \\
\text { xlb my } X \text {-axis label }\end{array}$ \\
\hline ylb & yaxlabel & $\mathbf{a} 24$ & $\begin{array}{l}\text { 24-character } Y \text {-axis label } \\
\text { ylb my } Y \text {-axis label }\end{array}$ \\
\hline $\begin{array}{c}\mathbf{x} \\
\text { ps } \\
\text { psc }\end{array}$ & & & $\begin{array}{l}\text { output to X-window, rsap.ps, rsap.psc, } \\
\text { rsap.meta } \\
\text { output to file rsap.ps } \\
\text { output to file rsap.psc } \\
\end{array}$ \\
\hline \#\#\# & & & Comment - ignored by RSAP \\
\hline
\end{tabular}




\section{Example Input Files}

Ten sample RSAP input files are described in this section. Each example corresponds to one of the sample plots displayed in Figures 1-10. The specifier "\#\#\# " introduces a comment line that is ignored by RSAP.

Note that the device specifier " $\mathrm{x}$ " sends the plot to four devices: an X plot window, a PLPLOT metafile rsap.meta, the color postscript file rsap.psc, and the monochrome postscript file rsap.ps. The postscript files may then be sent to the default printer:

$$
\text { "lpr -h rsap.ps" or "lpr -h rsap.psc". }
$$

A postscript file may be viewed via "ghostview -seascape rsap.psc".

A postscript file may be created without plotting to an $\mathrm{X}$ window by replacing the specifier "x" with "ps" or "psc".

\section{Example 1. One Plot in One Window}

This input compares JohnFow1235_990203.par and the final SAMMY parameter file SAMMY . PAR, reads JohnFow1235_990203.odf, and plots one frame (nxp=nyp=1) to an $\mathrm{X}$ window. The "deb" card specifies a plot of cross section data with error bars and the Bayes fit for $2200<\mathrm{E}<2500 \mathrm{keV}$ with y-axis limits of 0 and $1.0 \mathrm{~b}$. If axis limits are not specified, the plot will span the range of data values. Resonance energies and widths are displayed (keres $=1$, kgamres $=1$ ) on the plot. A blank card ends the input for this particular plot sequence and causes the plot to be drawn on the output device. The "q" in column 1 tells RSAP to quit. The "\#\#\#" comment card is ignored by the code.

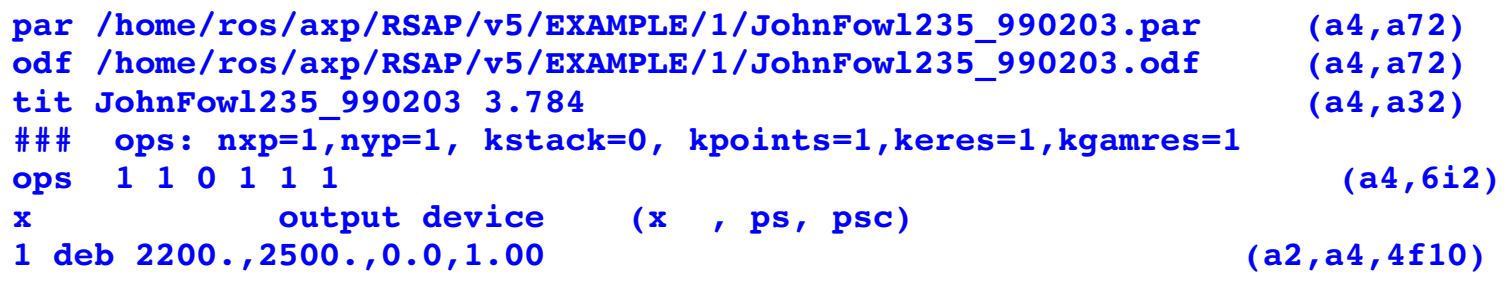

q

To make the above plot on your $\mathrm{X}$ terminal, type:

rsap < /home/ros/axp/RSAP/v5/EXAMPLE/1/inx

You should see a plot like the one in Figure 1. On your screen the background should be black. After RSAP reads the "deb" card and sends the plot to your screen, the code waits for a "RETURN" before reading the next input card.

Alternately, the " $x$ " and " 1 deb" cards could be replaced by one "oxp" card:

oxp 1 deb 2200.,2500.,0.0,1.00

$(a 4, a 2, a 4,4 f 10)$ 


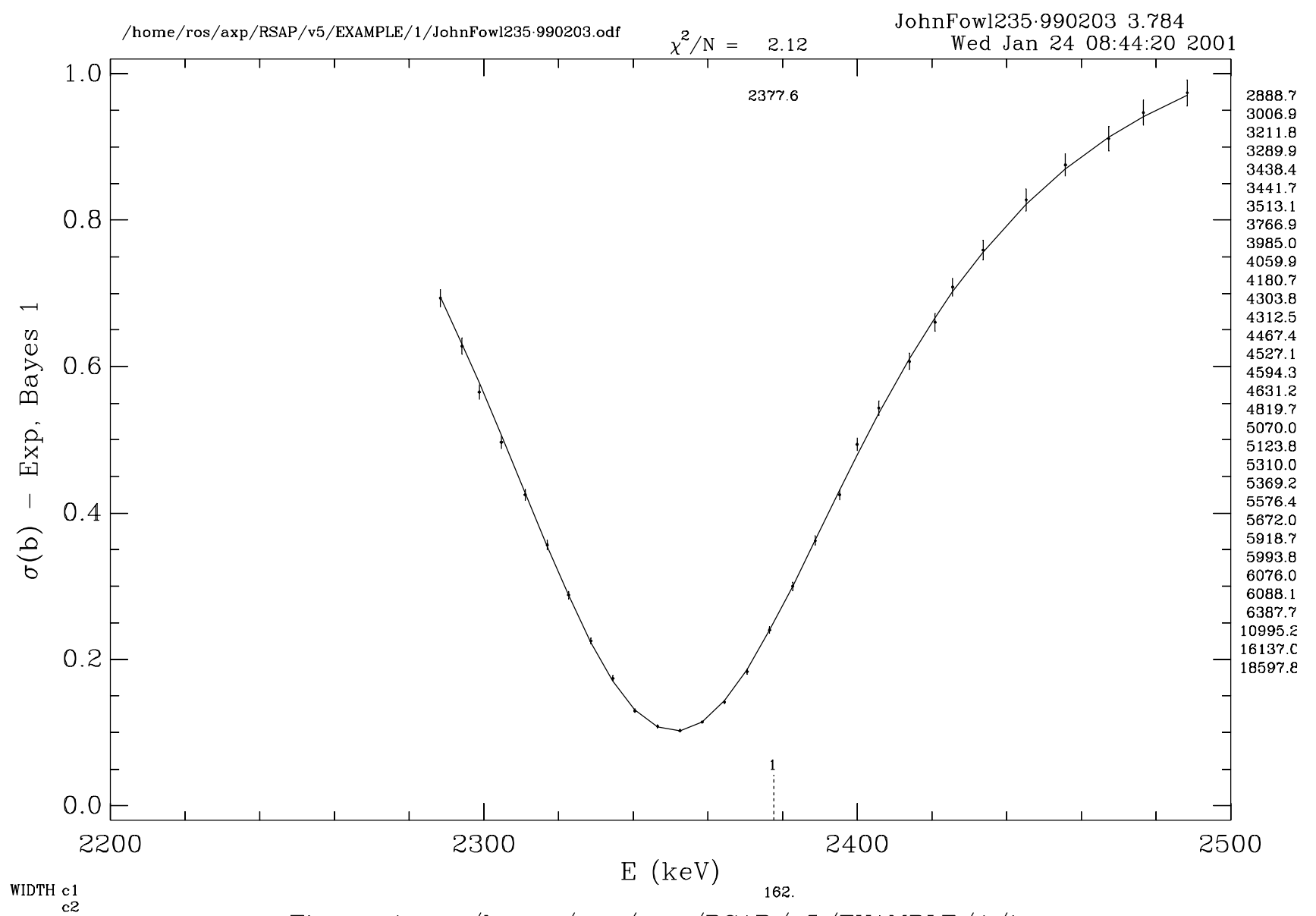

Figure 1. /home/ros/axp/RSAP/v5/EXAMPLE/1/inx

The "par", "tit", and "ops" specifiers are optional. The default "ops" values are:

$\begin{array}{ll}\mathrm{nxp}=\mathrm{nyp}=1 & (1 \text { plot in } \mathrm{x} \text { direction, 1 plot in y direction), } \\ \mathrm{kstack}=1 & (1 \text { plot per frame), } \\ \mathrm{kpoints}=0 & \text { (plot data as histograms), } \\ \text { keres }=\text { kgamres }=0 & \text { (no display of resonance energies, widths). }\end{array}$

Above the plot the ODF file name, title, date, and time are listed. If the SAMMY output file SAMMY.LPT exists, the conventional CHISQ/NDAT is also listed above the plot. If keres $=1$, spin group numbers are listed just above the bottom $\mathrm{x}$ axis, and resonance energies are listed just below the top $\mathrm{x}$ axis. Resonance energies greater than the $\mathrm{x}$-axis maximum are listed to the right of the plot. 
Example 2. Stack 2 frames in 1 window

To see an example of stacking 2 plots in a window ( Figure 2), type:

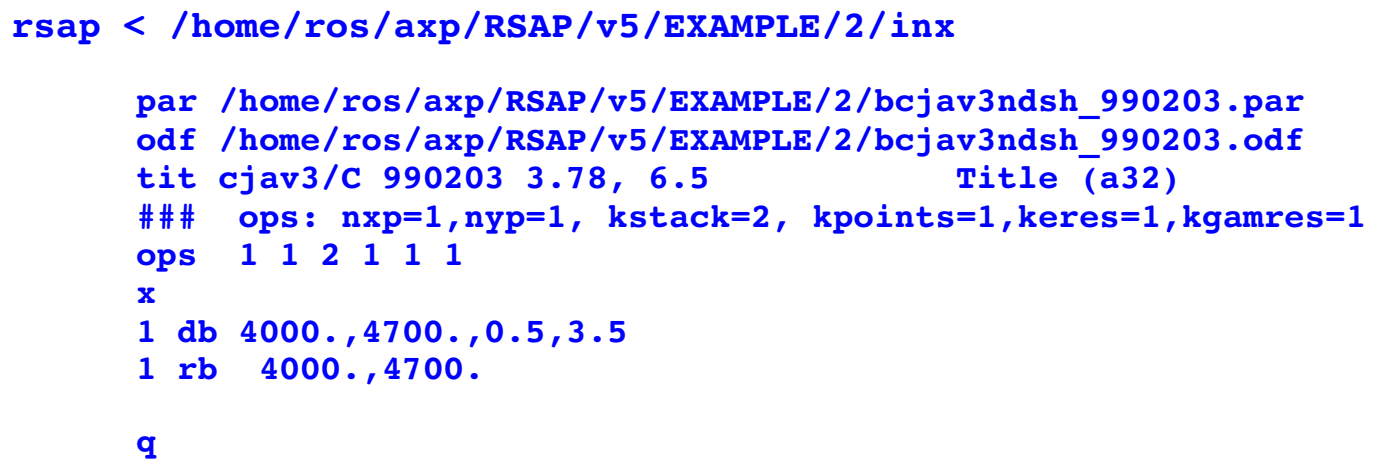

q

The upper plot in Figure 2 shows both the residuals (dots) and the Bayes fit.

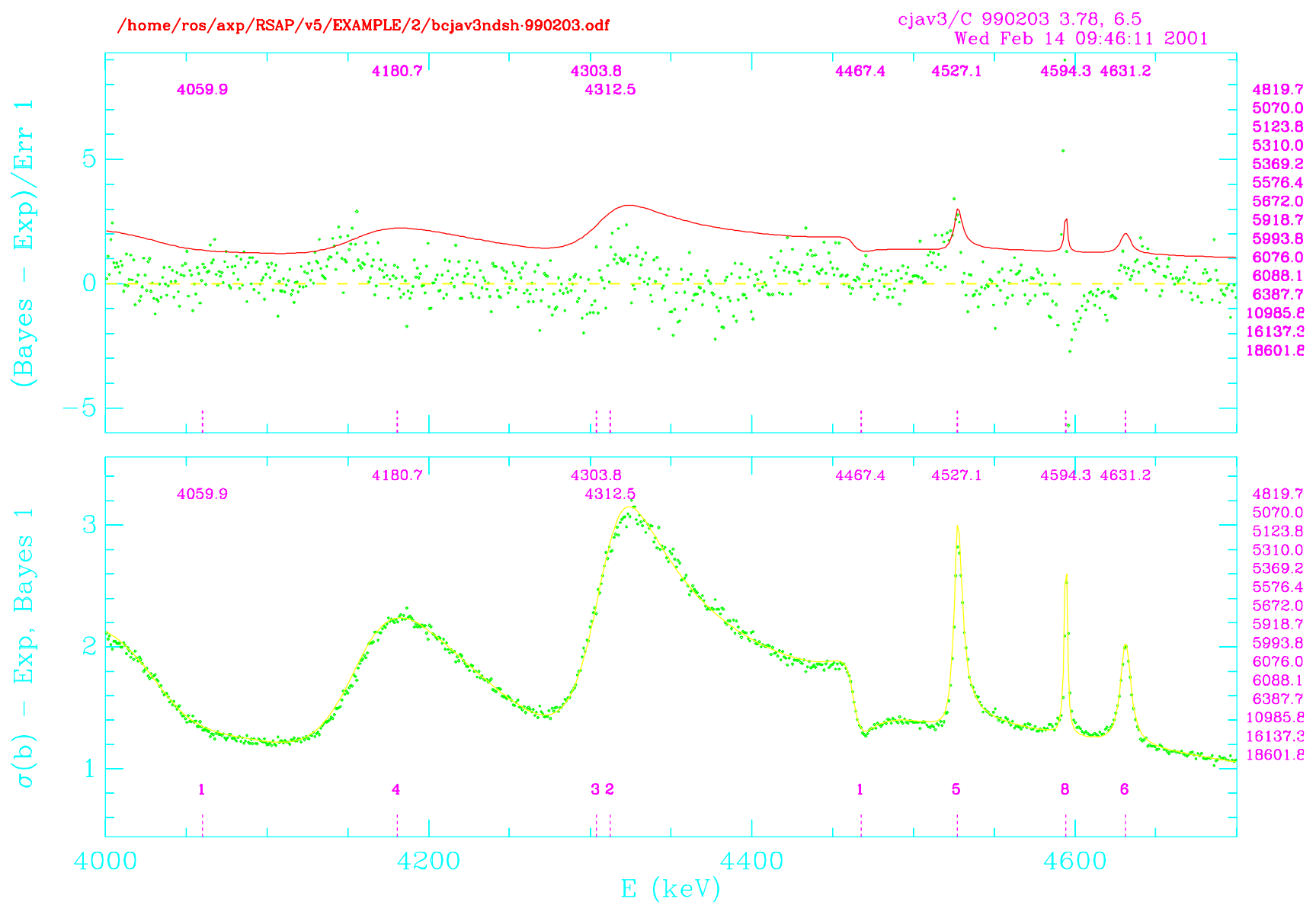

Figure 2. /home/ros/axp/RSAP/v5/EXAMPLE/2/inx 
Example 3. Plot from 2 ODF files

Plots from two ODF files may be stacked in one window:

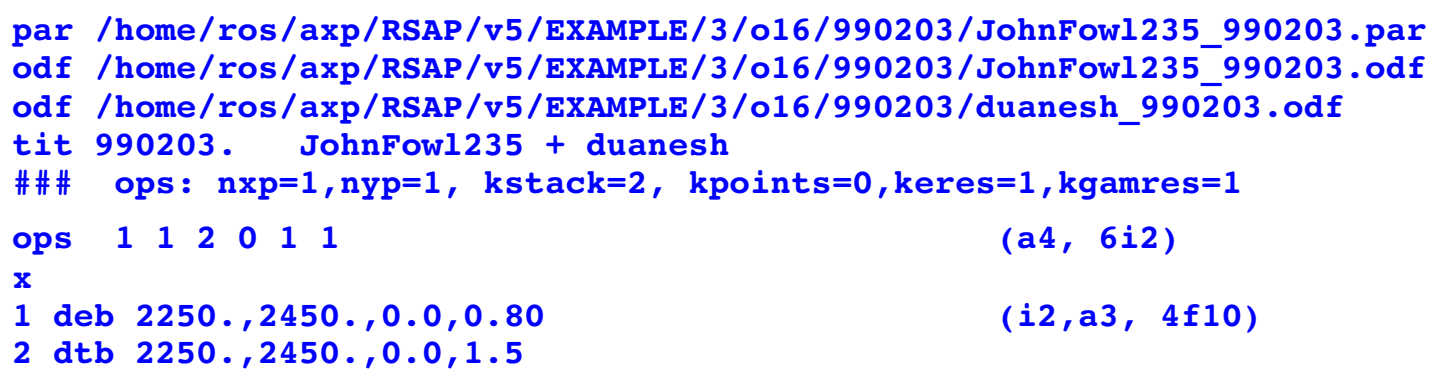

To make the above plot on your X terminal (see Figure 3), type:

rsap < /home/ros/axp/RSAP/v5/EXAMPLE/3/inxs2

Note that the code will terminate properly when the end of the input file is reached.

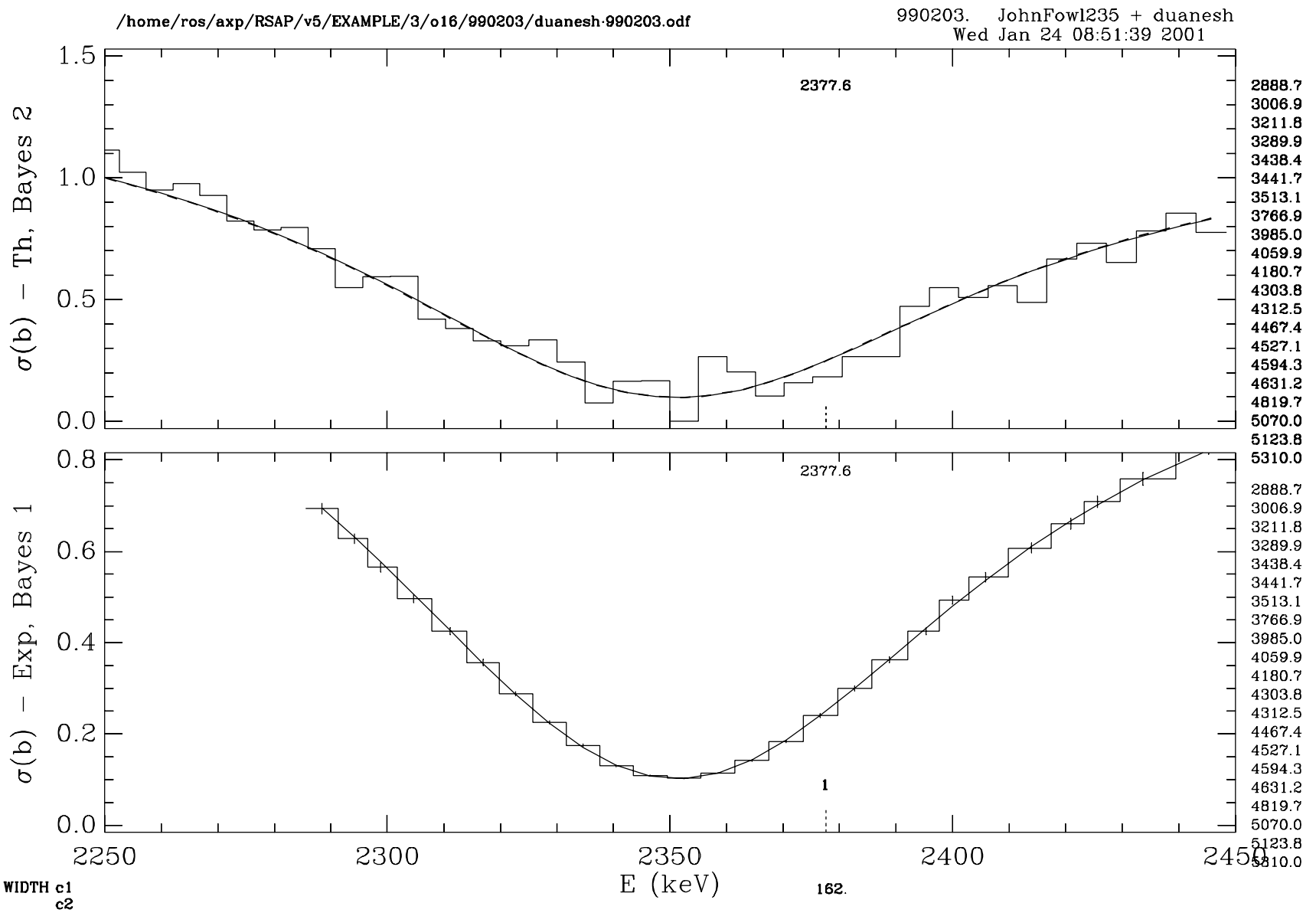

Figure 3. /home/ros/axp/RSAP/v5/EXAMPLE/3/inxs2 


\section{Example 4. Transmission plots}

Transmission data may be displayed by plot requests that begin with "a" or "b" instead of "1" or "2" as shown in the following sample input which contains two plot sequences. In the first sequence, transmission ("a det $0 ., 400,0.0,1.0 ")$ and total cross section data ("1 det 0.,400.") from the first ODF file are stacked in one frame in an X plot window (see Fig. 4A). The second sequence produces a similar plot (Fig. 4B) for the second ODF file. Note that the "lpr " specifier automatically sends the monochrome postscript file rsap.ps to the default printer.

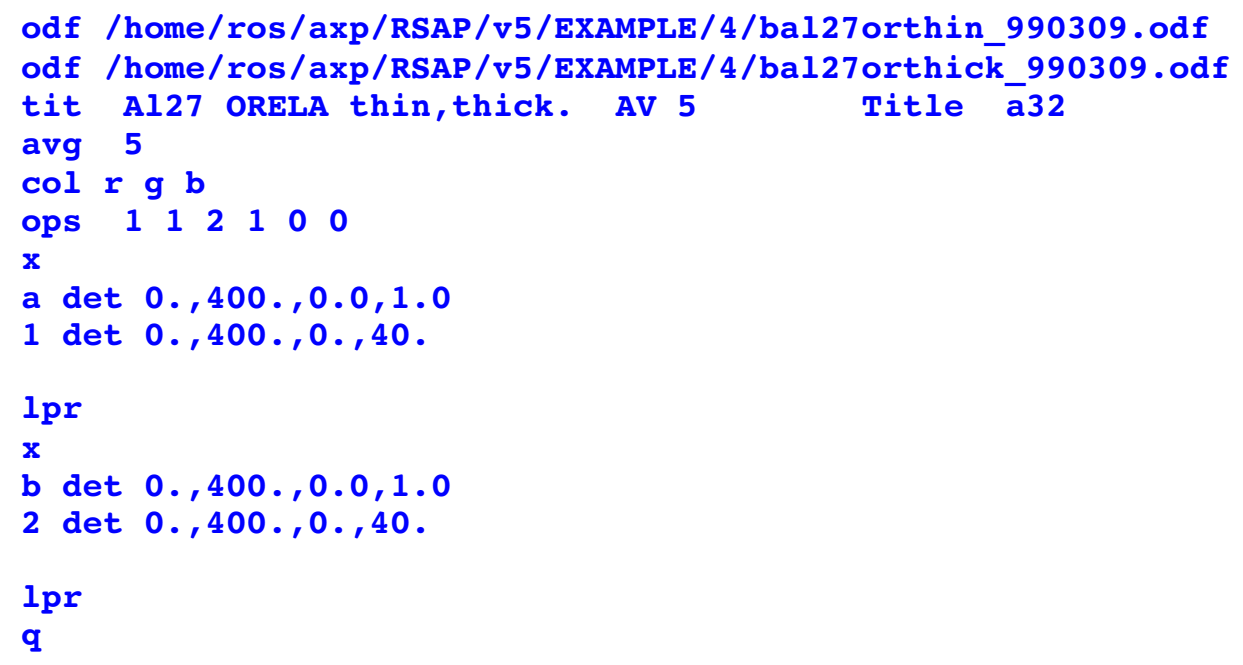

To make the above plots on your X terminal (see Figures 4a, 4b), type: rsap < /home/ros/axp/RSAP/v5/EXAMPLE/4/alortrantot

In this example the plot contains the text "<5>" at the top of the frame, indicating that 5 data points were averaged before plotting. 

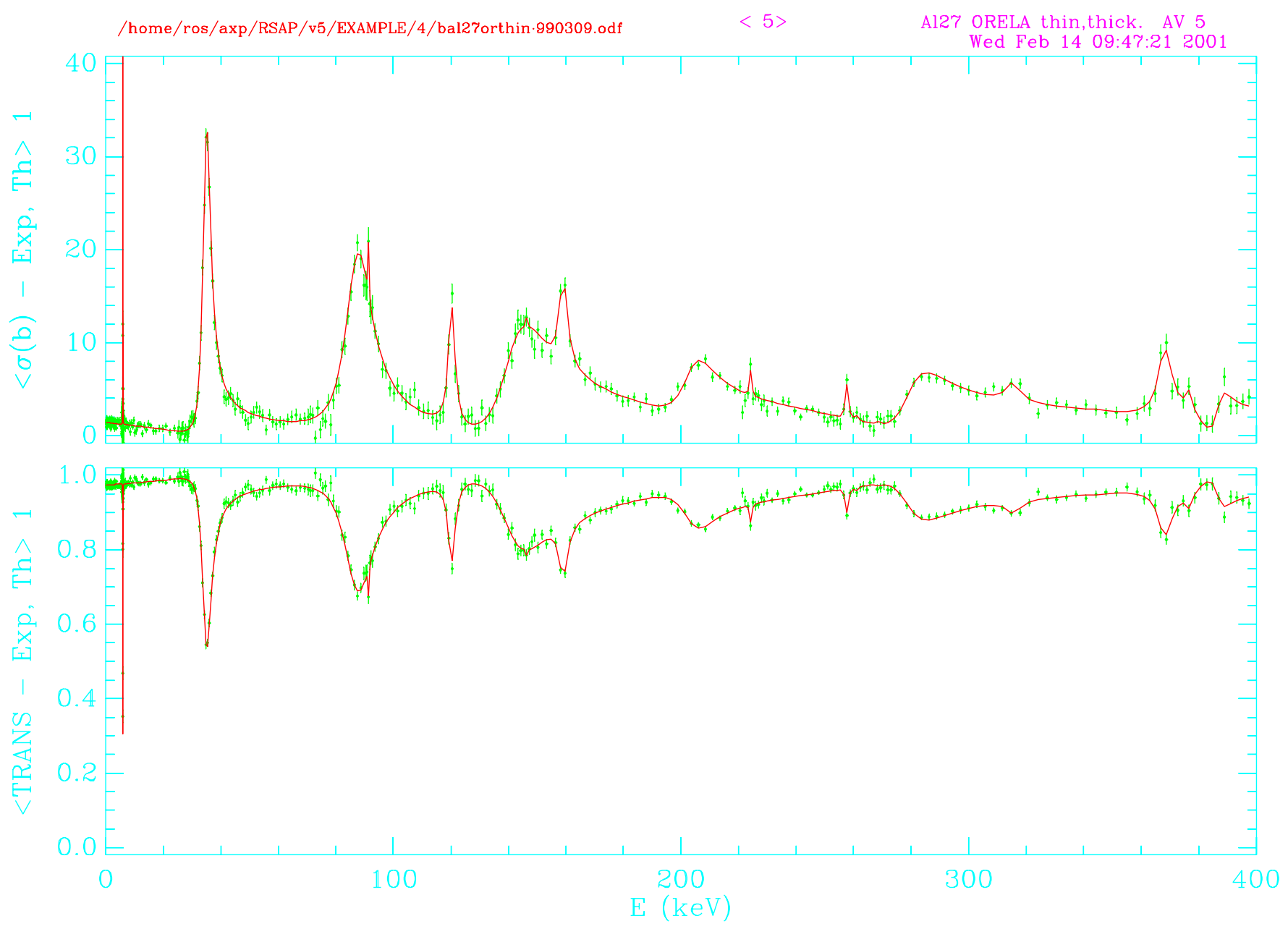

Figure 4A. /home/ros/axp/RSAP/v5/EXAMPLE/4/alortrantot 

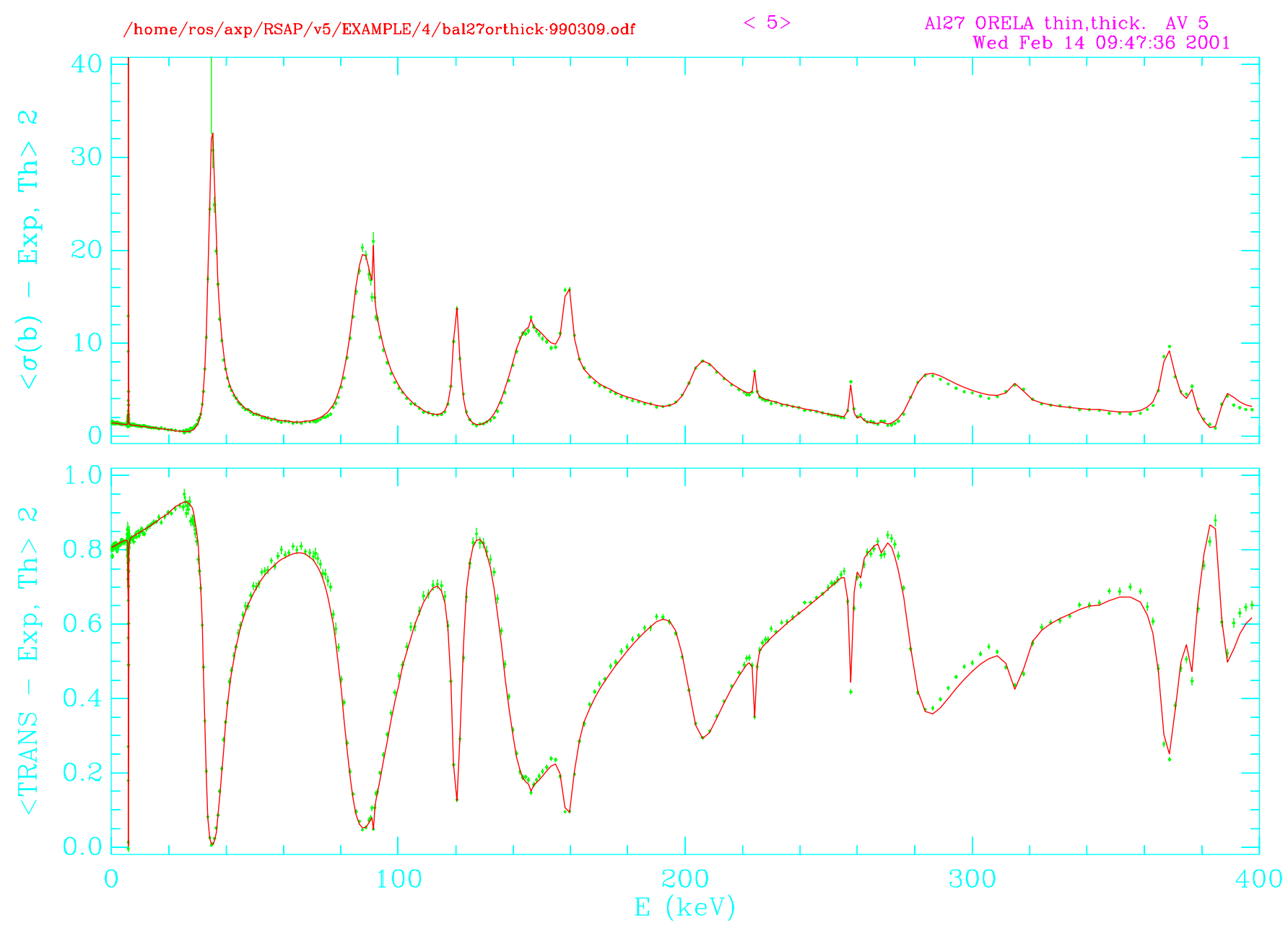

Figure 4B. /home/ros/axp/RSAP/v5/EXAMPLE/4/alortrantot 
Example 5. Colors, Fonts, and Annotation

Colors, fonts, and annotation with a character string are illustrated by the following input file:

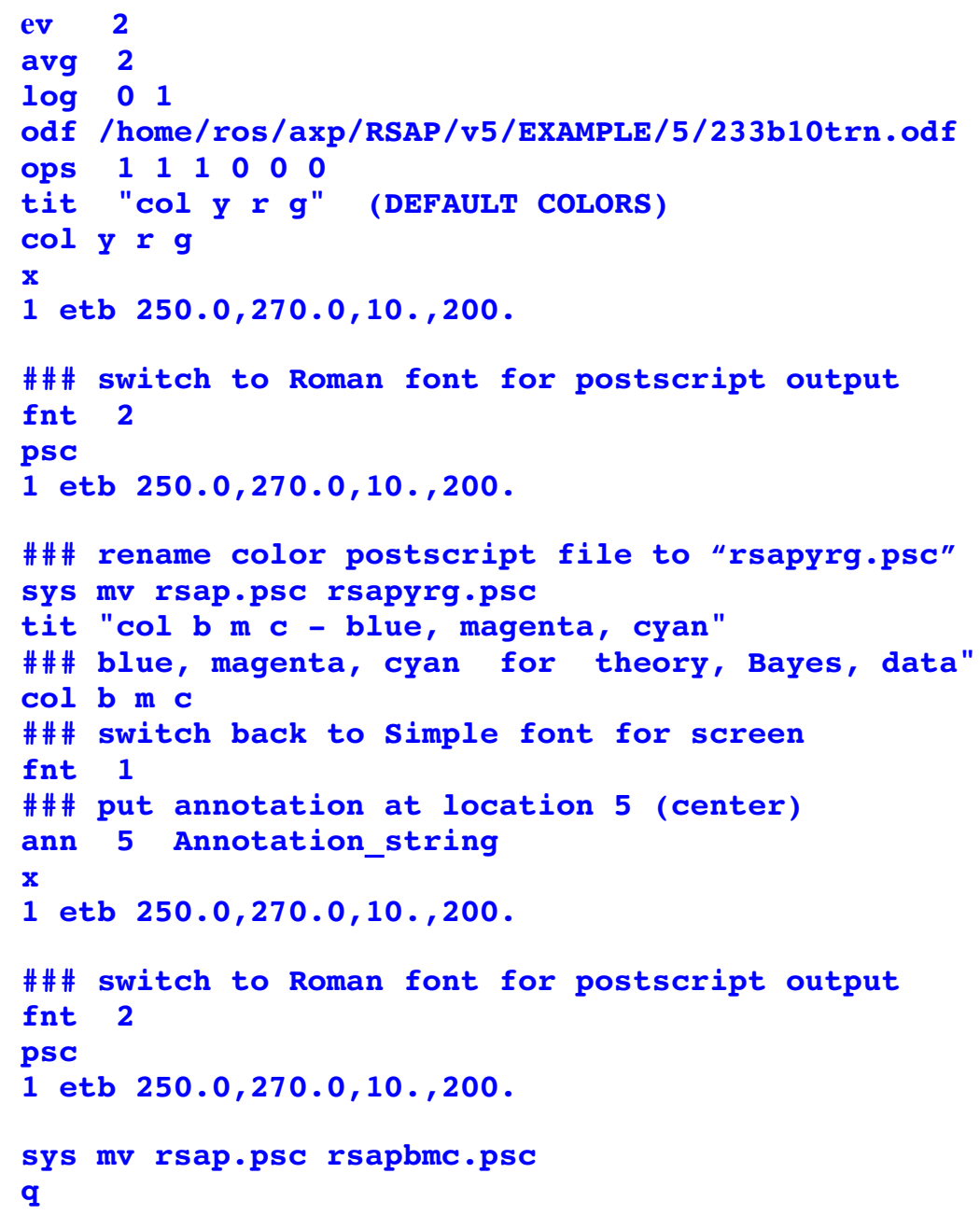

To make the above plots on your X terminal (see Figure 5), type:

rsap < /home/ros/axp/RSAP/v5/EXAMPLE/5/incolxpsc 


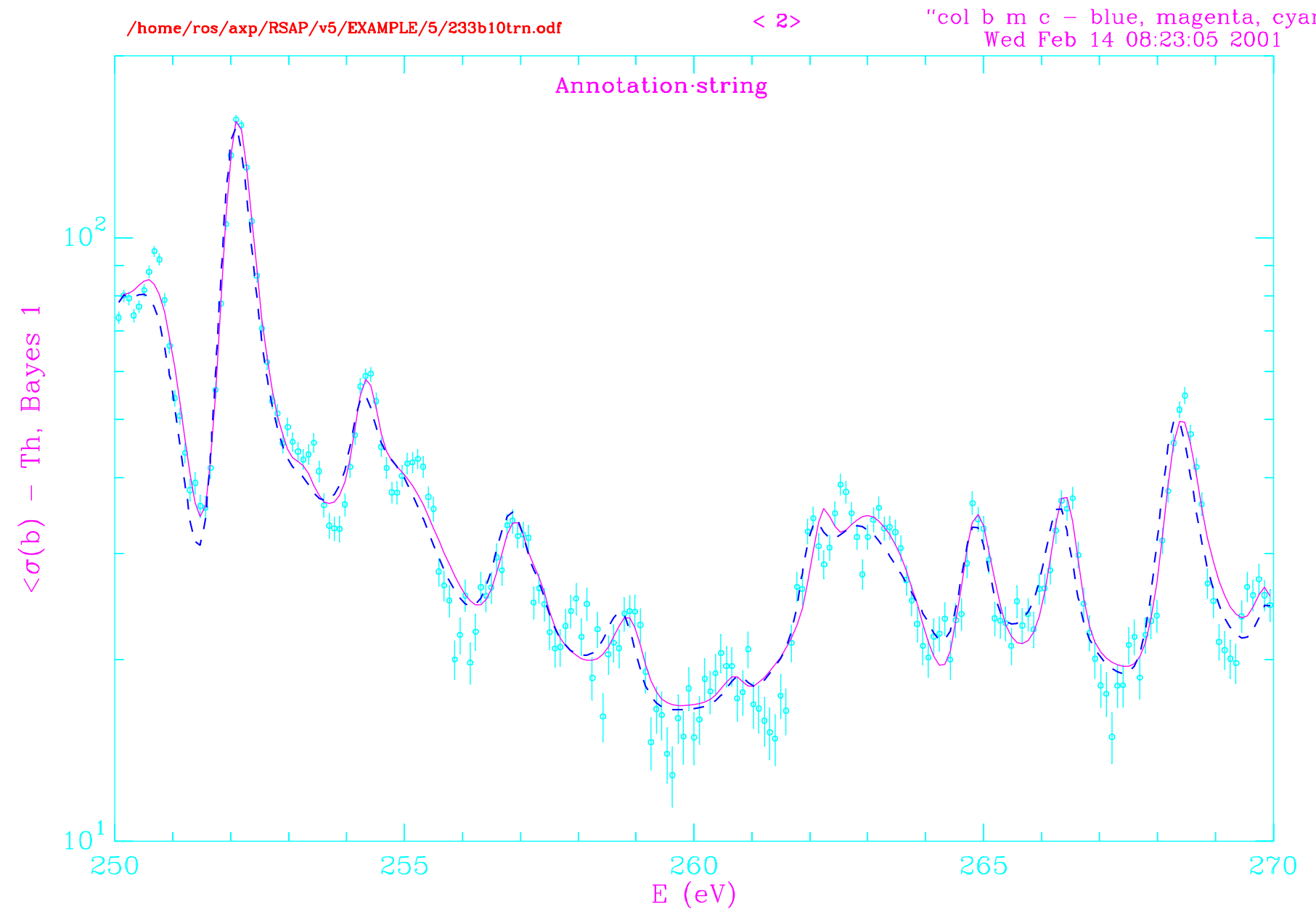

Figure 5. /home/ros/axp/RSAP/v5/EXAMPLE/5/incolxpsc 


\section{Example 6. Figure Captions using "cap"}

A 64-character figure caption string may be written at the bottom edge of the plot window with the cap specifier. Vertical axes are scaled to fit plots and caption in the window. An example is given in Figure 6, which was produced by the file :

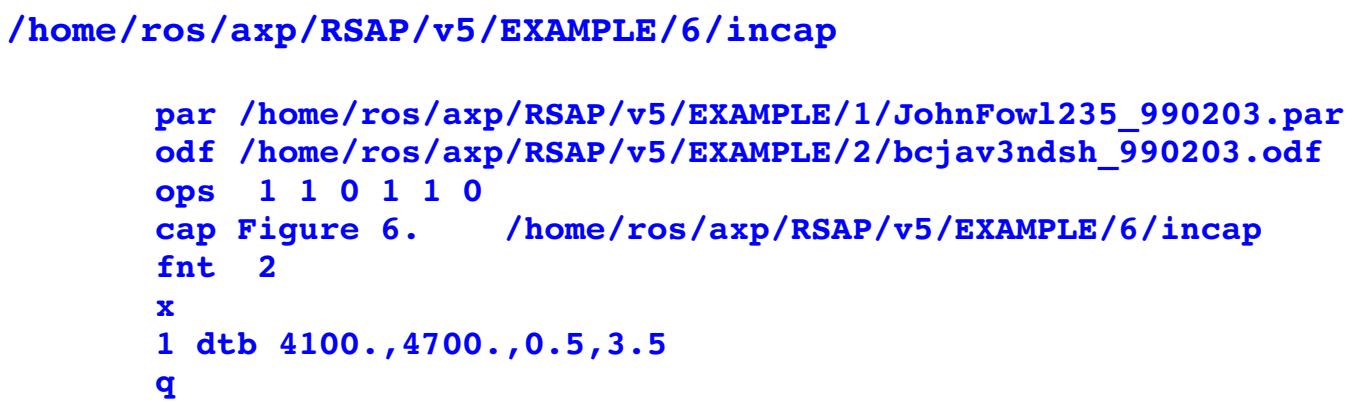

Figure captions are supported for the case of one plot per page in the x-direction, i.e. $\mathrm{nxp}=1($ ops 1).

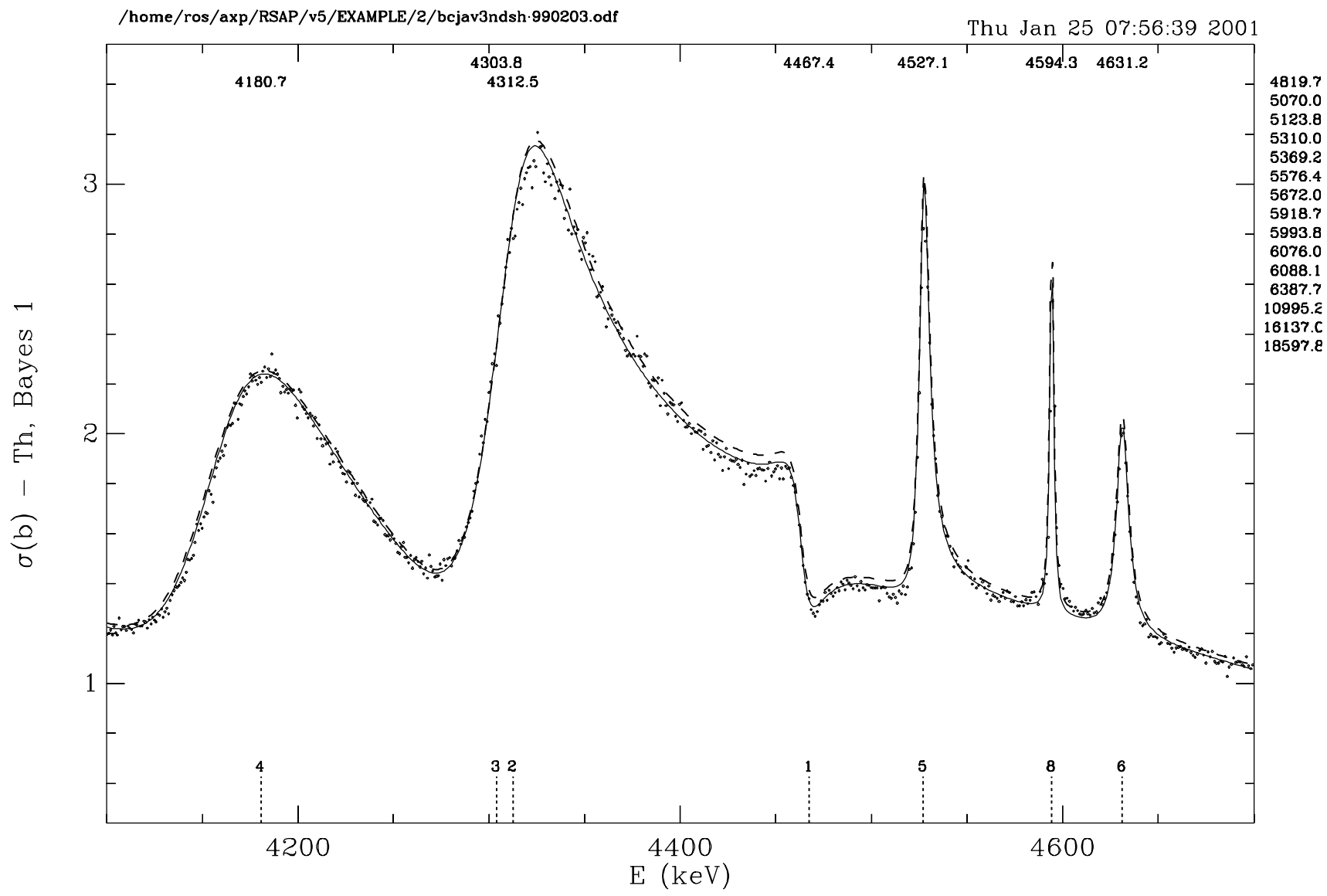

Figure 6. /home/ros/axp/RSAP/v5/EXAMPLE/6/incap 
Example 7. Plotting from 3 ODF Files and Annotation Strings

Plotting from 3 ODF files and annotation strings are illustrated in Figure 7, which was produced by the command:

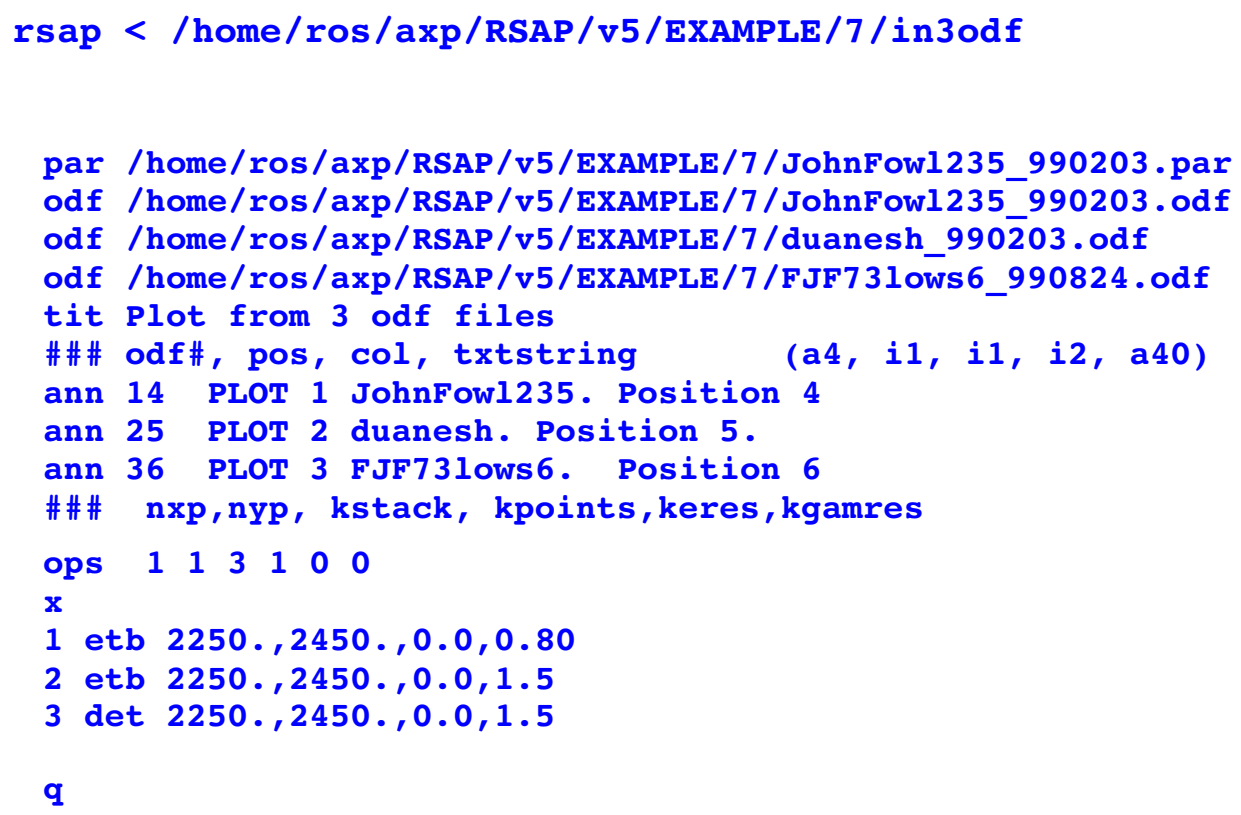

The ann specifier can be used to position a text string at the left (4), center (5), or right (6) of the plot. 

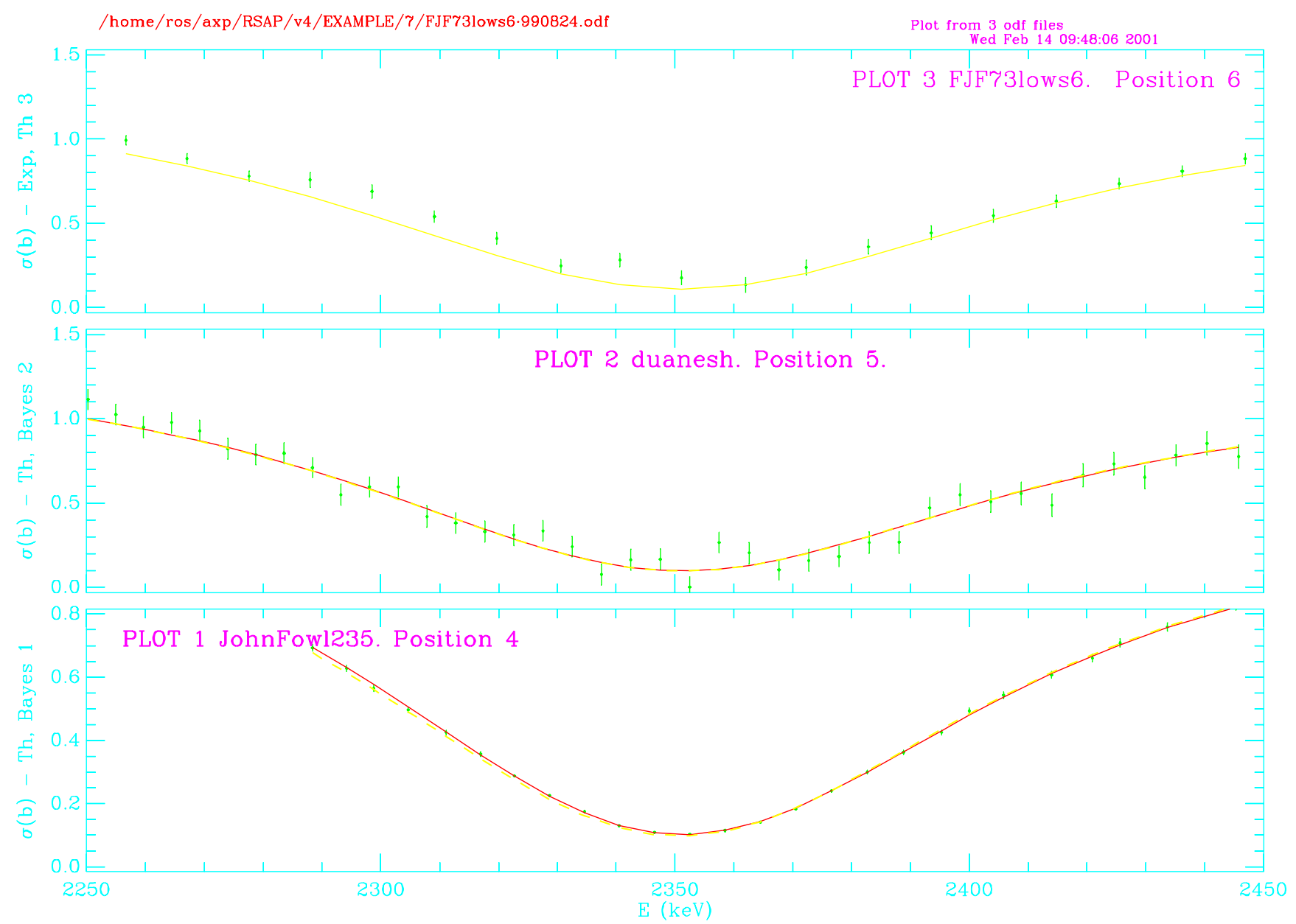

Figure 7. /home/ros/axp/RSAP/v5/EXAMPLE/7/in3odf 
Example 8. Place 6 Plots in 1 Window

To put plots from 6 ODF files in a single window in a $2 \times 3$ xy matrix and send the file rsap.ps to the default printer:

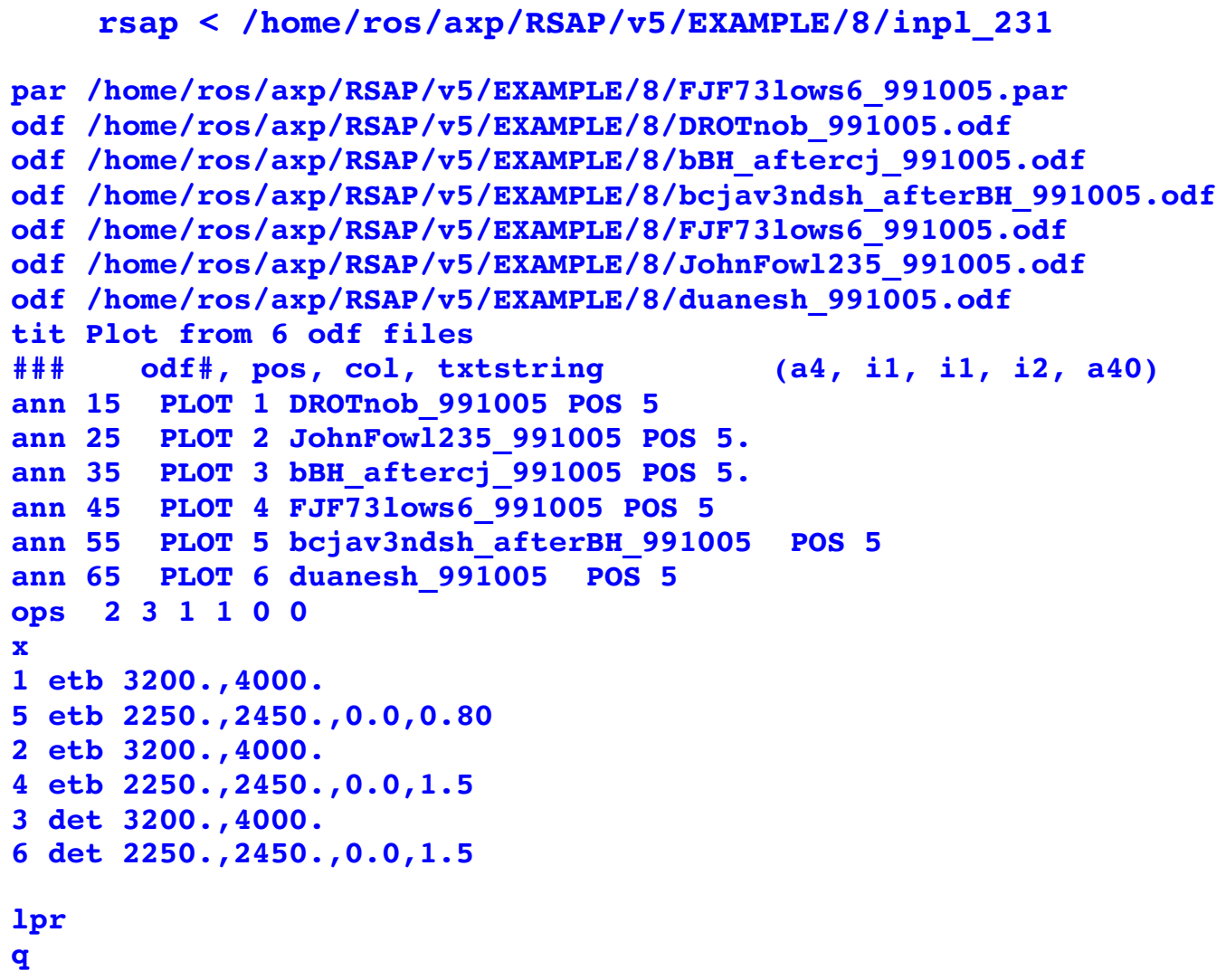

Other sample input files in the EXAMPLE / 8 directory will plot in a $3 \times 2$ xy matrix (in6odf_321), and in a 6x1 xy matrix (in6odf_stack6). 

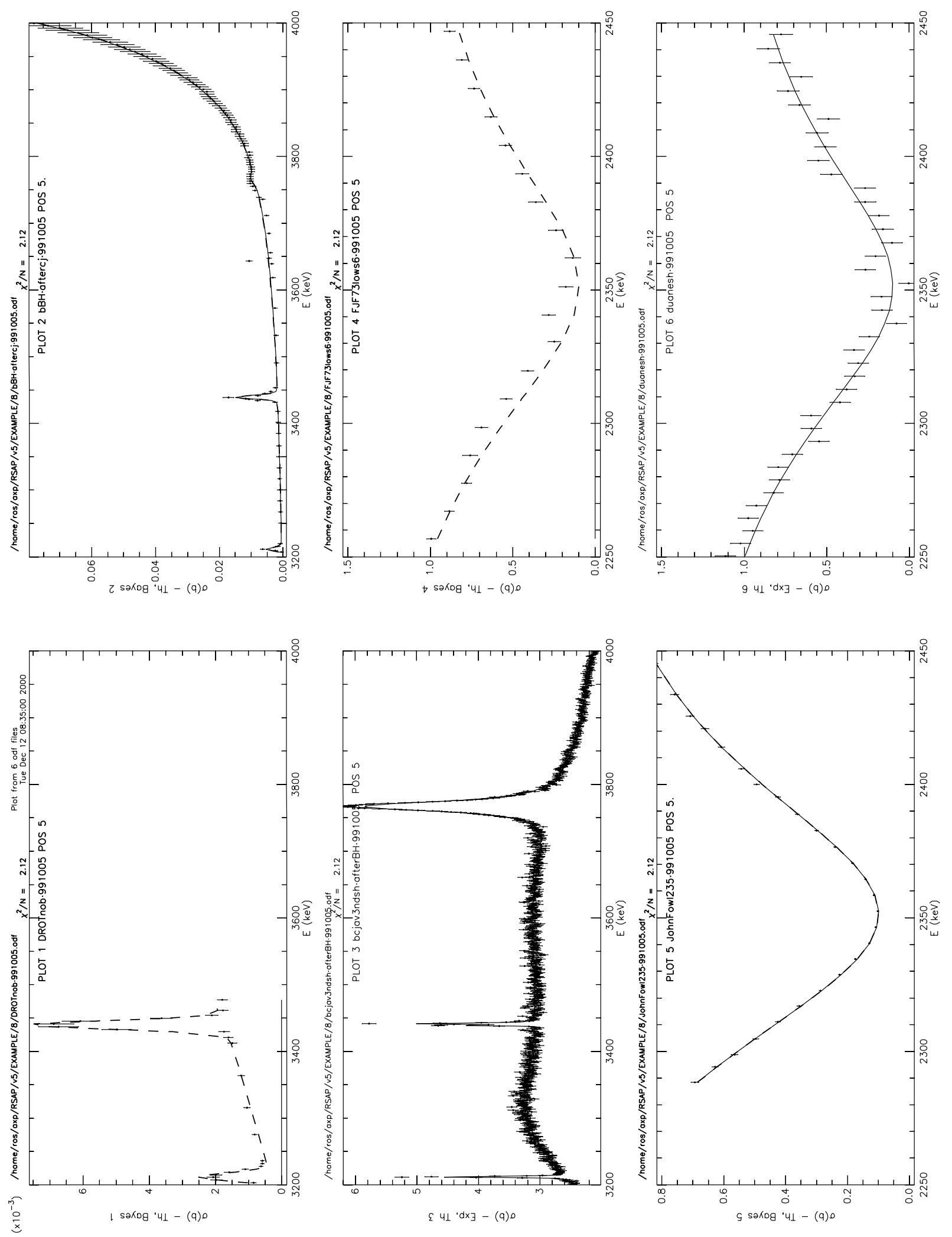

 
Example 9. Overlay 6 Plots in 1 Window

The number of plots to be overlaid is determined by the ovr specifier. To overlay plots from 6 ODF files in a window (see Figure 9) :

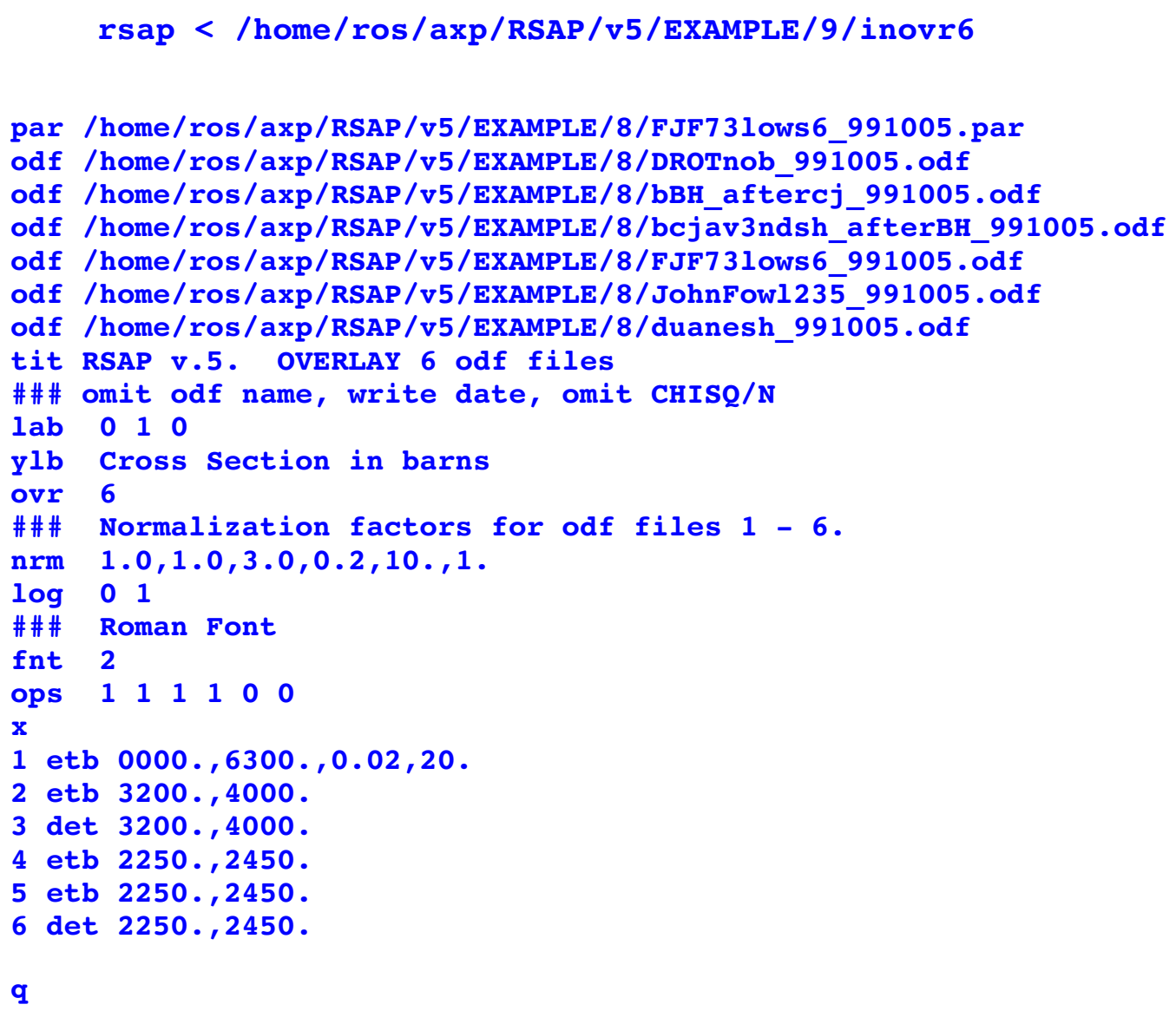

q

Normalization factors were applied to each plot with the $\mathrm{nrm}$ specifier, and the $\mathbf{l a b}$ specifier was used to inhibit output of the odf name and CHISQ/NDAT to the plot. 


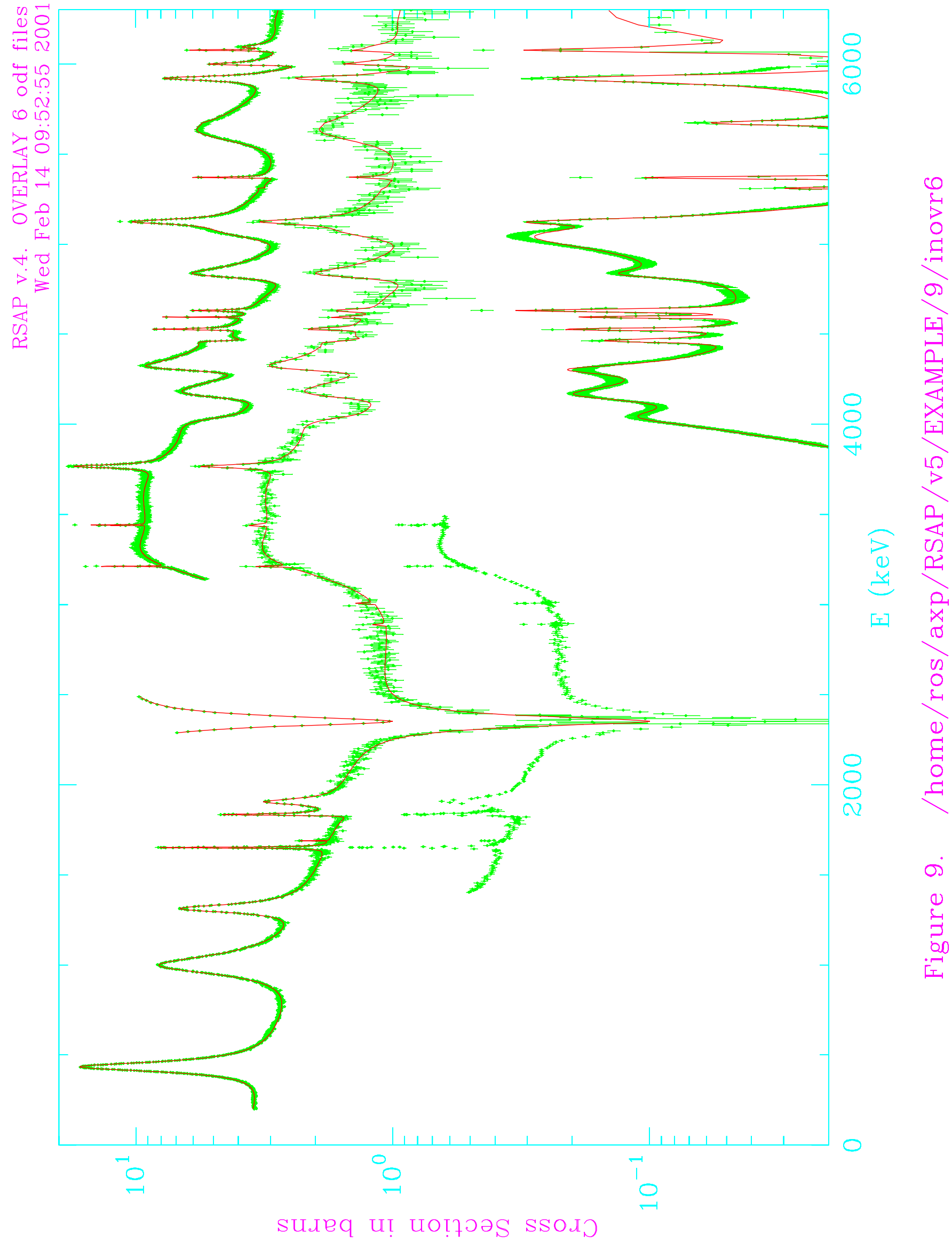




\section{Example 10. Text Strings using "txt"}

Text strings may be written at user $(x, y)$ locations with the $t x t$ specifier. String size, orientation, and color may be specified as illustrated in Figure 10, which was produced by the file :

\section{/home/ros/axp/RSAP/v5/EXAMPLE/10/intxt}

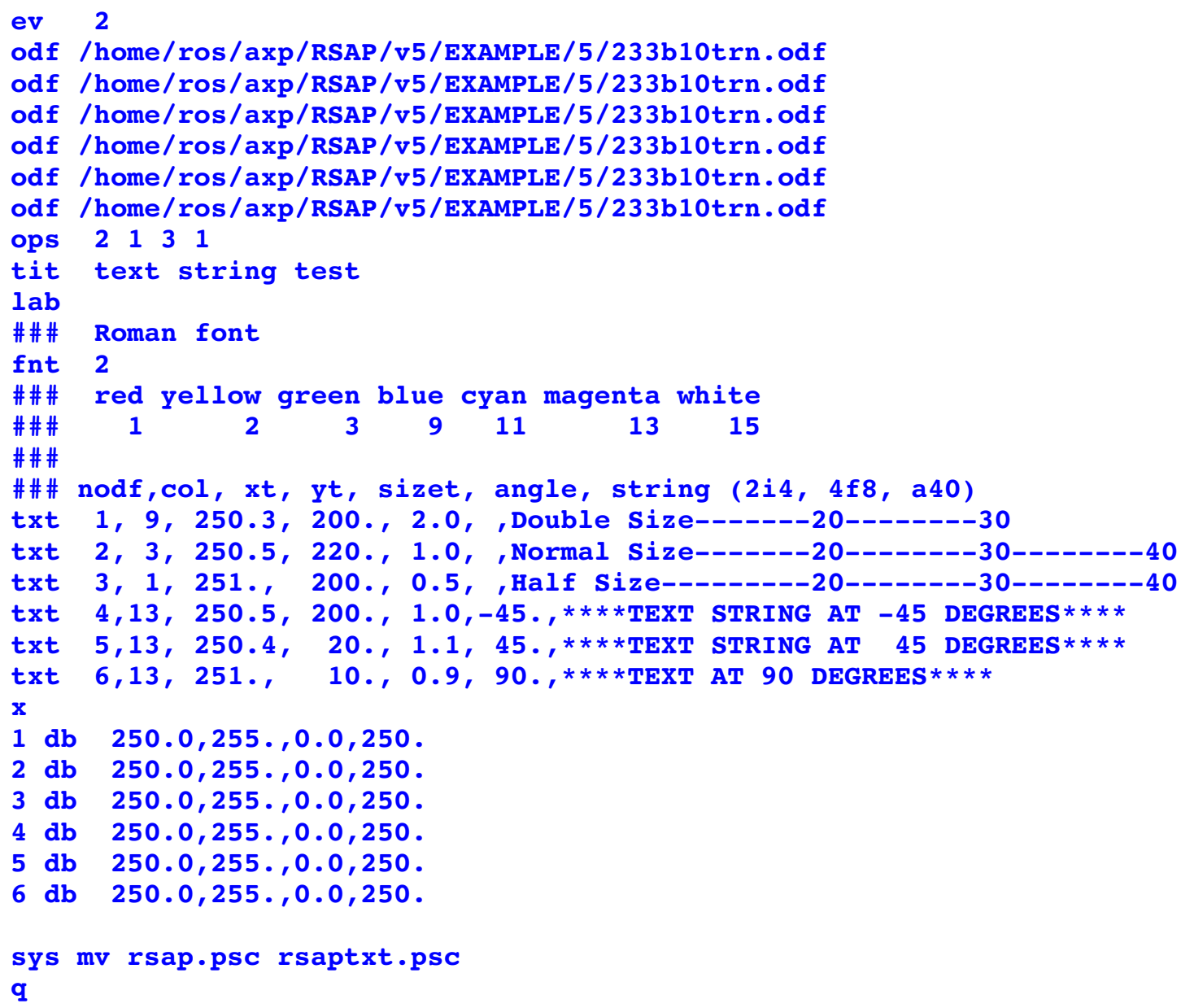



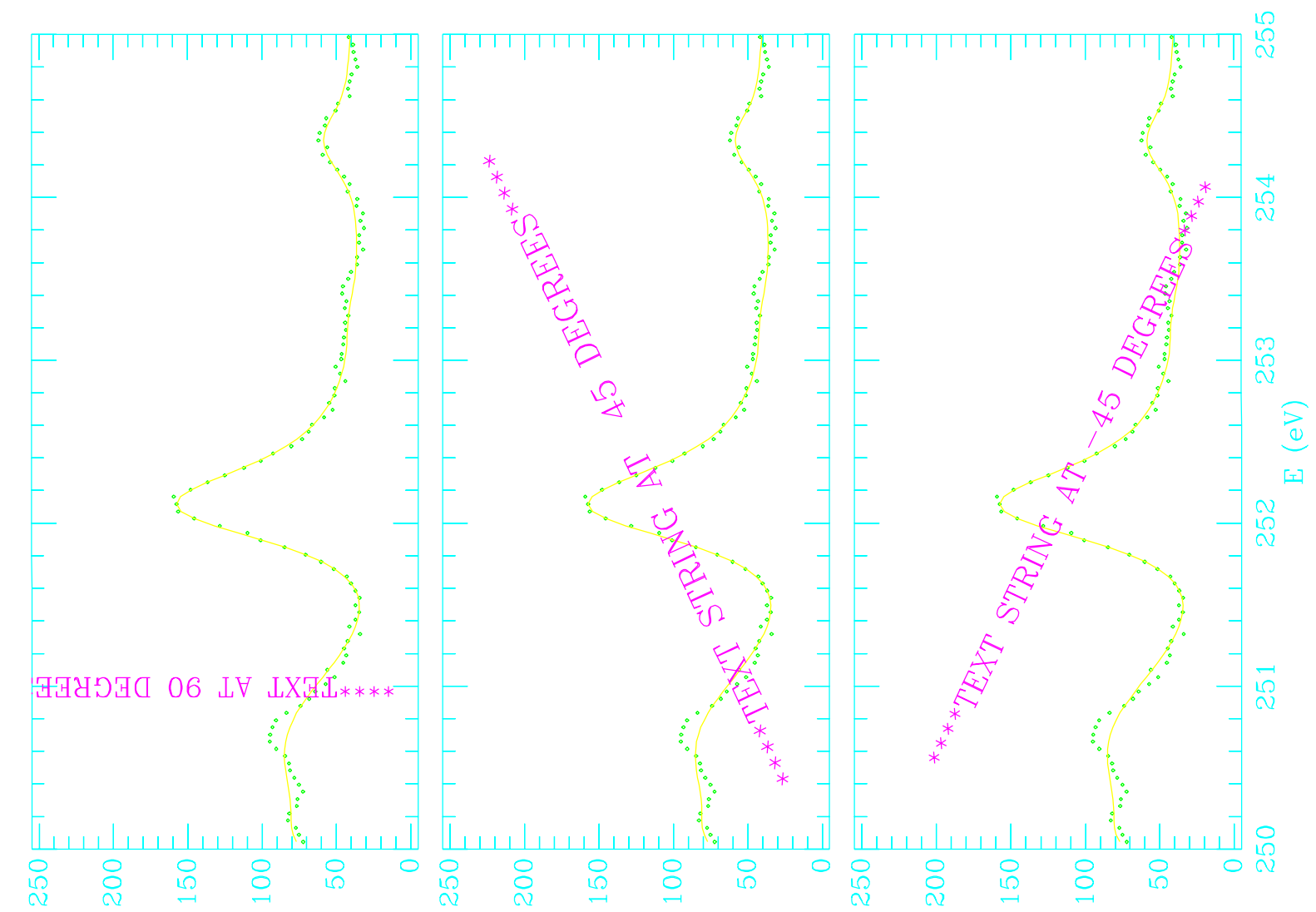

9 səКeg 'dx日 - (q)。

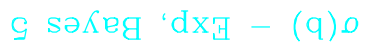

f səKeg “dx' - (q)
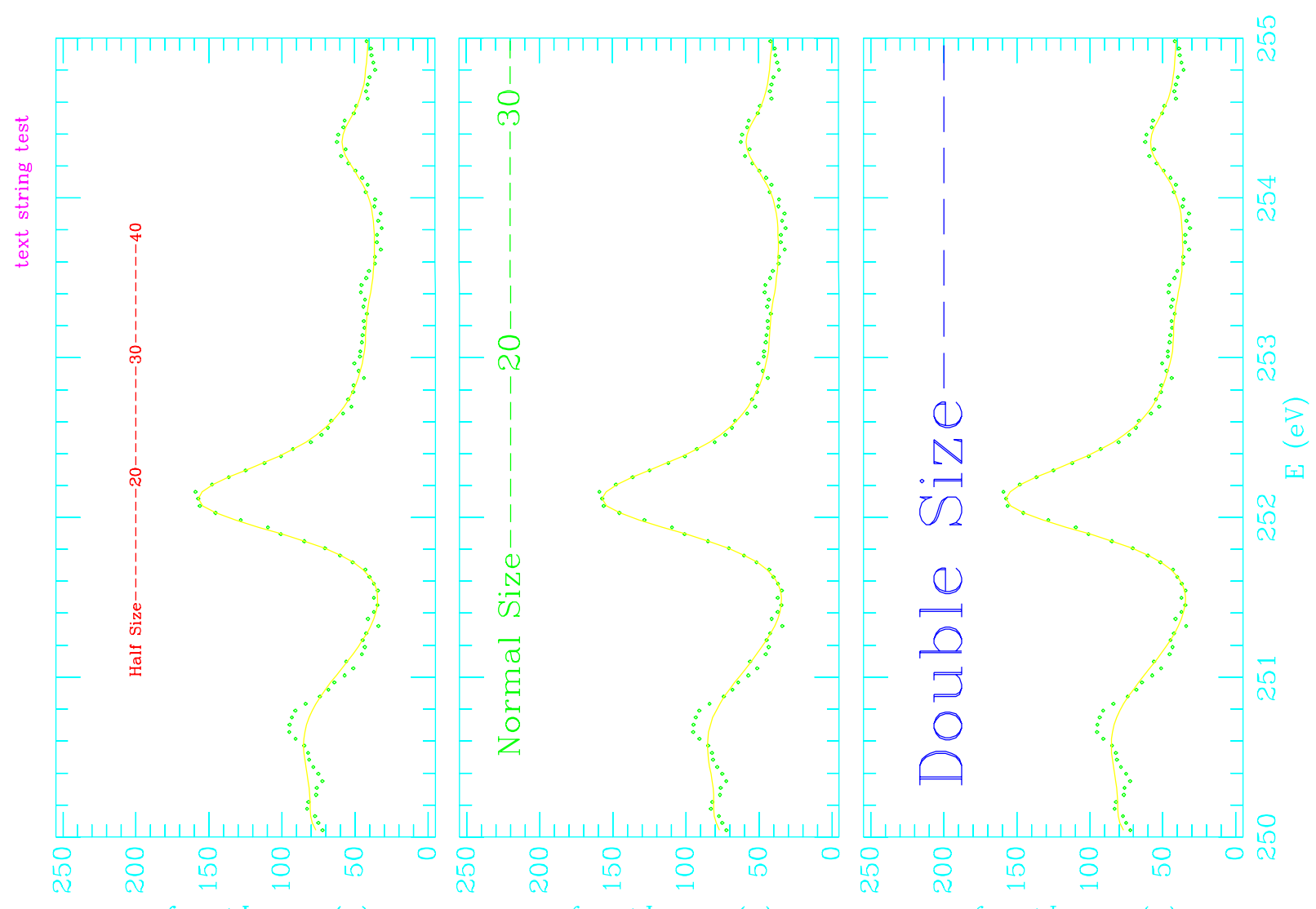

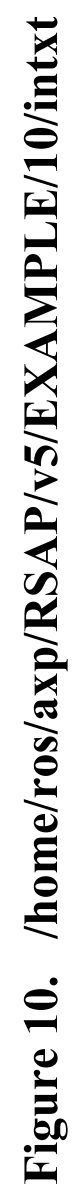

E səКeg 'dx' - (q)

z səKeg 'dx' - (q)o

I səKeg “dx' - (q) 0 


\section{Peak Search and Fitting}

A peak search procedure has been implemented in RSAP to provide an initial PAR file for use with SAMMY. The procedure, an adaptation of the method of Mariscotti [3], is based on computation of the second derivative of the data averaged over a width parameter, fwhm. A second parameter, bias, is approximately the number of standard deviations above background for a peak to be found. A peak search is requested with the "pks" specifier.

pks fwhm, bias, a2targ, Itarg, Jtot, gamgam, fwhmax $(a 4,7 f 10)$

where fwhm is the full width at half-maximum (FWHM) in $\mathrm{eV}$, bias is the sensitivity parameter, a2targ is the mass number of the target, Itarg is the target spin (I), Jtot is the total spin $(\mathrm{J})$, gamgam is the capture width in eV (default 1.0), and fwhmax is the maximum value in $\mathrm{eV}$ allowed for the FWHM of a peak.

RSAP searches for peaks in the total cross section data in the energy range specified and estimates the width, height, and area of each peak found. The data and a sum of SLBW (single-level Breit-Wigner) shapes are then plotted. RSAP writes an output file, rsap.peaks, containing a list of energy, gamma width $\Gamma_{\gamma}$, neutron width $\Gamma_{\mathrm{n}}$, fission widths, and flags in the format of the SAMMY PARameter file. Estimates of the peak height $\sigma_{\mathrm{o}}$, total width $\Gamma$, statistical factor $\mathrm{g}$, and wave number $\mathrm{k}$, are used to estimate $\Gamma_{\mathrm{n}}$ and the fission width, $\Gamma_{\mathrm{f}}$.

$$
\begin{aligned}
4 \pi \mathrm{g} \Gamma_{\mathrm{n}} & =\sigma_{\mathrm{o}} \mathrm{k}^{2} \Gamma \\
\Gamma_{\mathrm{f}} & =\Gamma-\Gamma_{\gamma}-\Gamma_{\mathrm{n}}
\end{aligned}
$$

After a peak search, the "sam" specifier will tell RSAP to create a SAMMY input file, rsap.samin, do a SAMMY Bayes run with the input PAR file rsap.peaks, and plot the results. An example input file is reproduced below.

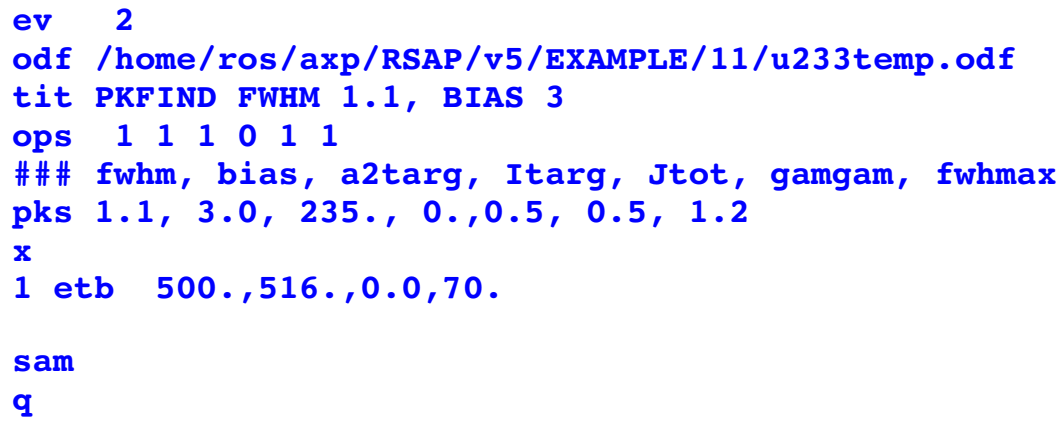

To run this example and plot on your X terminal (see Figure 11), type:

rsap < /home/ros/axp/RSAP/v5/EXAMPLE/11/tranxps

On the first plot (Fig. 11A) the solid line is the sum of SLBW shapes, and the dashed line is the SLBW sum plus a linear background computed from the first and last data points. On the second plot (Fig. 11B) the solid line is the SAMMY Bayes fit, and the dashed line is the SAMMY theory (initial theoretical value). 


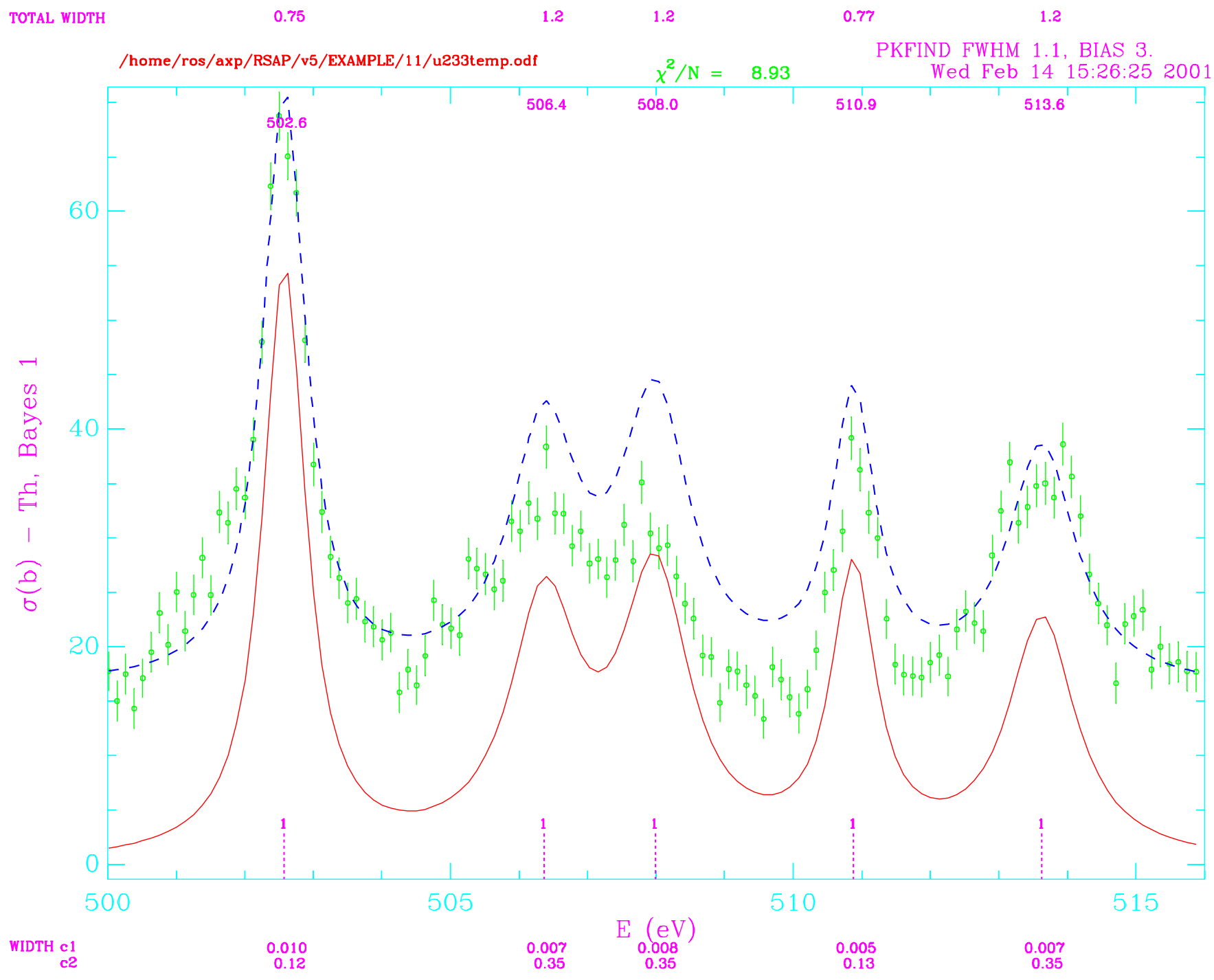

Figure 11A. /home/ros/axp/RSAP/v5/EXAMPLE/11/tranxps 


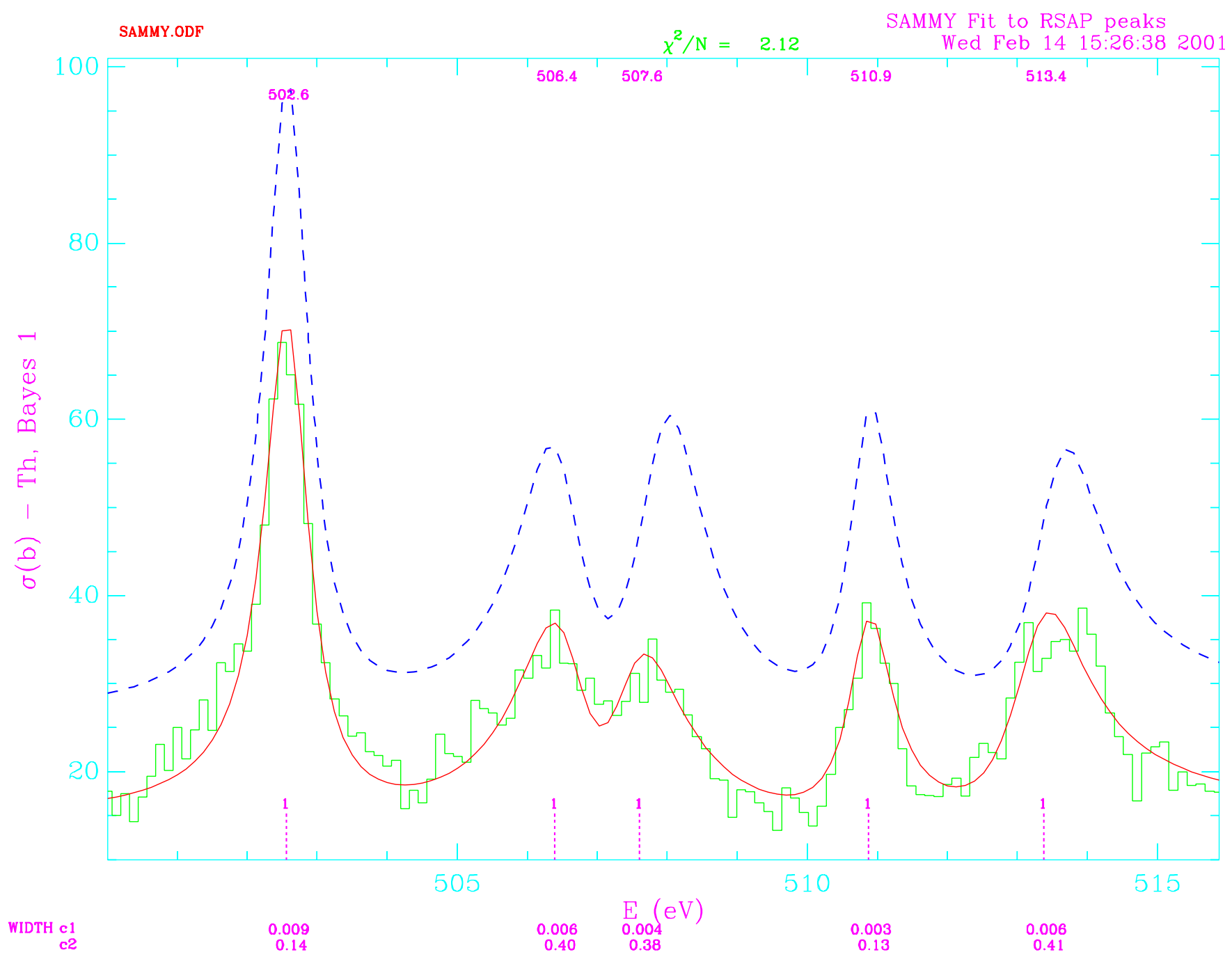

Figure 11B. /home/ros/axp/RSAP/v5/EXAMPLE/11/tranxps 


\section{Automatic Spin Group Variation (SGV)}

The process of fitting neutron cross section data with SAMMY often requires the user to try several spin values in order to obtain the best fit for a given resonance or group of neighboring resonances. Each trial requires several steps: a) editing the PAR file to change the spin group number, b) running SAMMY, c) viewing the results, and d) comparison with results from other trials.

An automatic spin group variation (SGV) procedure has been implemented in RSAP to facilitate the determination of spin group values for resonances. A simple RSAP input file allows the user to specify SAMMY input and PAR files, one or more resonances, an energy range for the fit, and up to 8 spin groups for each resonance. For each specified spin group, RSAP automatically edits the PAR file, runs SAMMY, and writes out CHISQ/NDAT and final resonance parameters. The required specifiers and their arguments are :

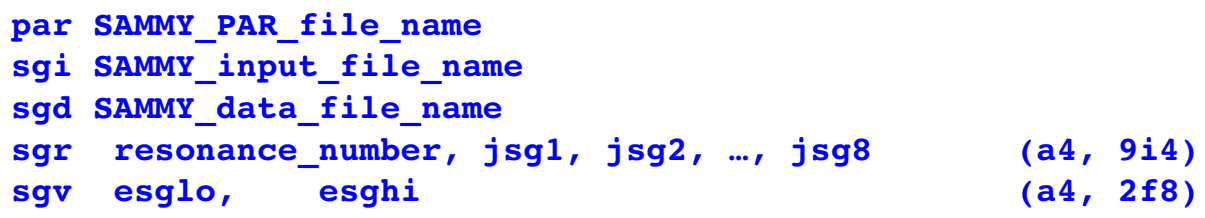

The resonance_number corresponds to the record number in the PAR file, and $j \mathbf{s g} i$ is the spin group number to be used for the $i^{\text {th }}$ SAMMY fit. The action specifier sgv tells RSAP to loop over the indicated spin groups, fitting over the energy range $(\mathrm{eV})$ from esglo to esghi . If a plot is wanted, the user should insert sgp after sgv. An example file with resonance 25 and spin groups 3,5 , and 6 is reproduced below.

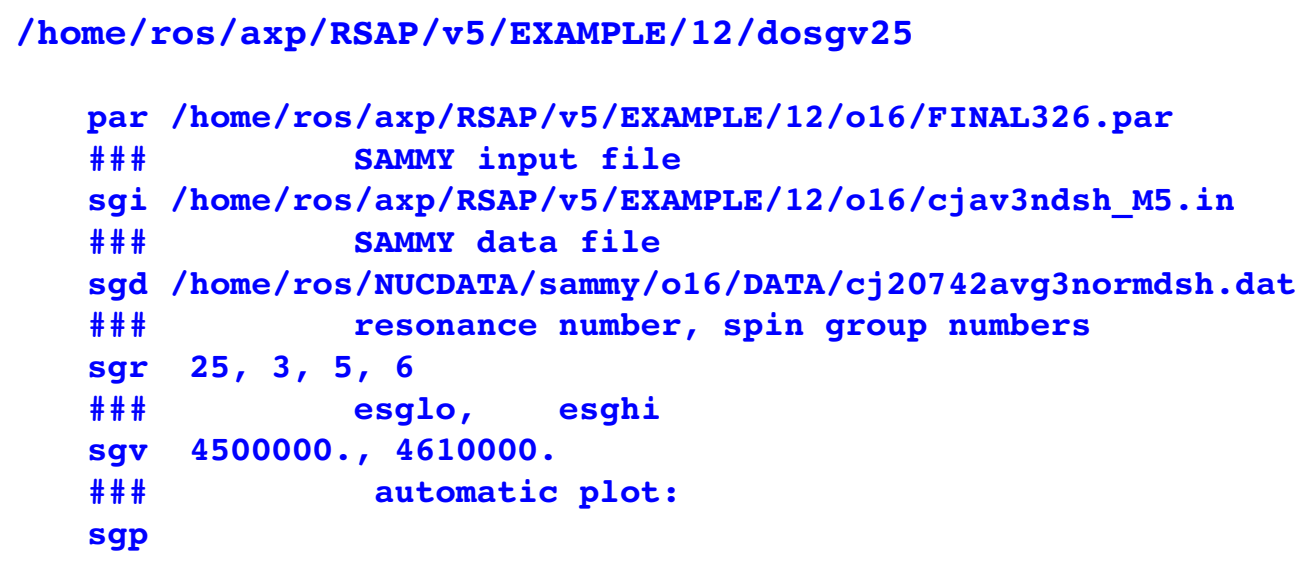

All parameters flagged in the user's original PAR file are varied in the SAMMY fits. RSAP does not modify the original PAR and INP files.

ODF and final PAR files for each spin group fit are saved in the subdirectory 00_00, which is created by RSAP. A repeat SGV run causes 00_00 to be deleted and re-create $\bar{d}$. For the above example, the saved files are:

$$
\begin{aligned}
& \text {./00_00/SG_25_03.PAR } .100 \_00 / \text { SG_25_03.0DF } \\
& \text {.100_00/SG_25_05.PAR .100_00/SG_25_05.0DF } \\
& \text {./00_00/SG_25_06.PAR ./00_00/SG_25_06.0DF }
\end{aligned}
$$

The file names are written on the "sgp" plot as shown in Figure 12.A. 

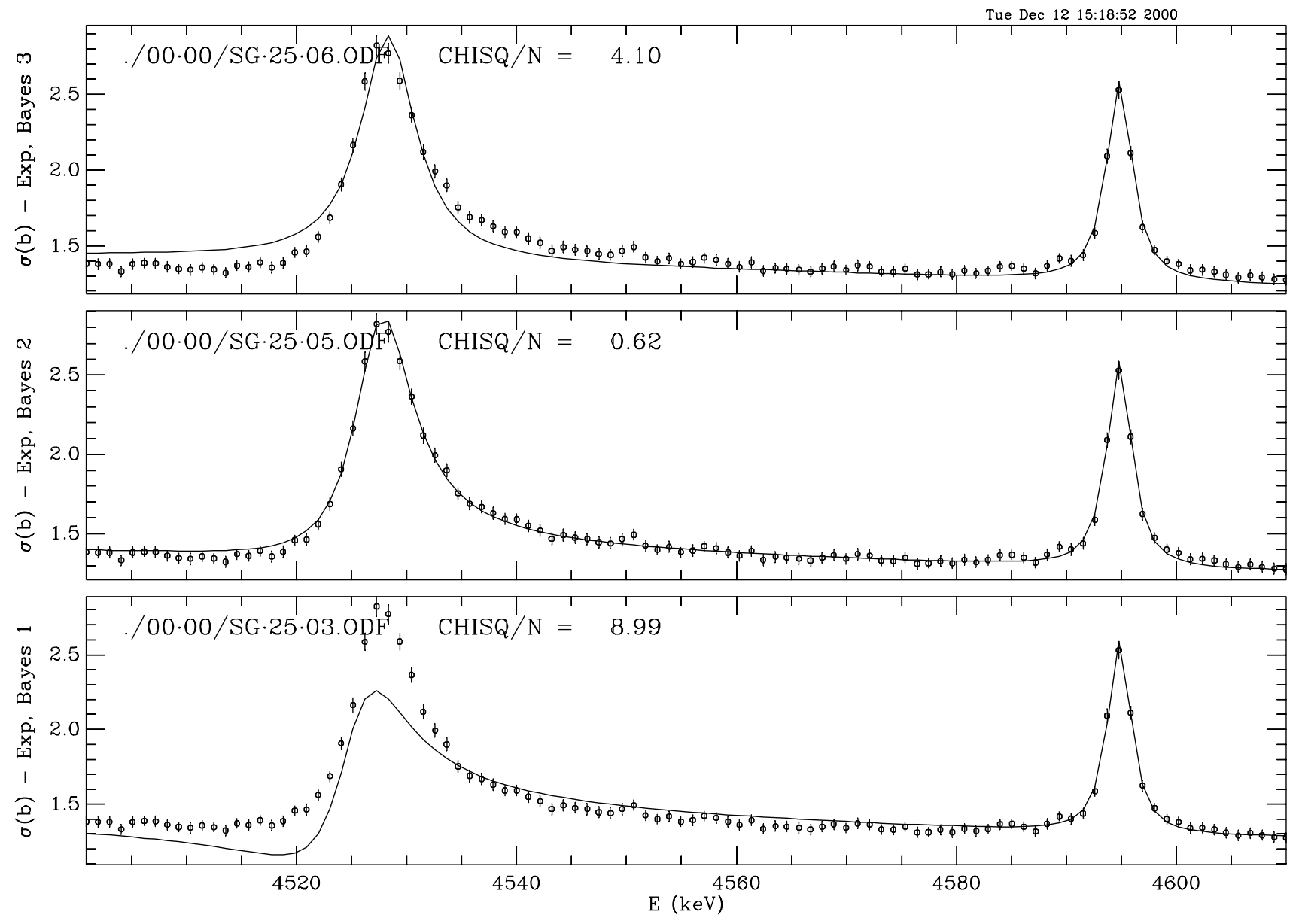

Figure 12A. /home/ros/axp/RSAP/v5/EXAMPLE/12/dosgv25

Fit results are written to files rsap.chi and rsap.sgvout:

RSAP SGV : Here is file rsap.chi

\begin{tabular}{rcrrrrrr}
\multicolumn{2}{r}{ Resonance 25} & & & \\
Resonance Group & CHISQ/NDAT & Eres $(\mathrm{eV})$ & Ggamma & Gneutron \\
25 & 3 & 8.9857 & 4524740.526 & $2.5000 \mathrm{E}+02$ & $6.3516 \mathrm{E}+06$ & $8.8506 \mathrm{E}+05$ \\
25 & 5 & 0.6202 & 4527389.229 & $2.5000 \mathrm{E}+02$ & $4.9415 \mathrm{E}+06$ & $1.1957 \mathrm{E}+06$ \\
25 & 6 & 4.1012 & 4528243.660 & $2.5000 \mathrm{E}+02$ & $4.6382 \mathrm{E}+06$ & $1.1648 \mathrm{E}+06$
\end{tabular}

RSAP SGV : Here is file rsap.sgvout:

$\begin{array}{rrrrrrrrrr}\text { Eres }(\mathrm{eV}) & \text { Ggamma } & \text { Gneutron } & \text { Gfiss } 1 & \text { Gfiss2 } & & & \\ 4524740.526 & 2.5000 \mathrm{E}+02 & 6.3516 \mathrm{E}+06 & 8.8506 \mathrm{E}+05 & 1 & 0 & 1 & 3 & 200.00 \\ 4527389.229 & 2.5000 \mathrm{E}+02 & 4.9415 \mathrm{E}+06 & 1.1957 \mathrm{E}+06 & 1 & 0 & 1 & 1 & 5 & 200.00 \\ 4528243.660 & 2.5000 \mathrm{E}+02 & 4.6382 \mathrm{E}+06 & 1.1648 \mathrm{E}+06 & 1 & 0 & 1 & 6 & 200.00\end{array}$


An alternate way of indicating sequential spin groups is illustrated by the command

$$
\text { sgr } 25,-3,-7
$$

This command tells RSAP to do SAMMY fits for spin groups 3 through 7 for resonance 25 .

Figure 12.B. shows output produced with the RSAP input file

\section{/home/ros/axp/RSAP/v5/EXAMPLE/12/dosgv25_3thru7}

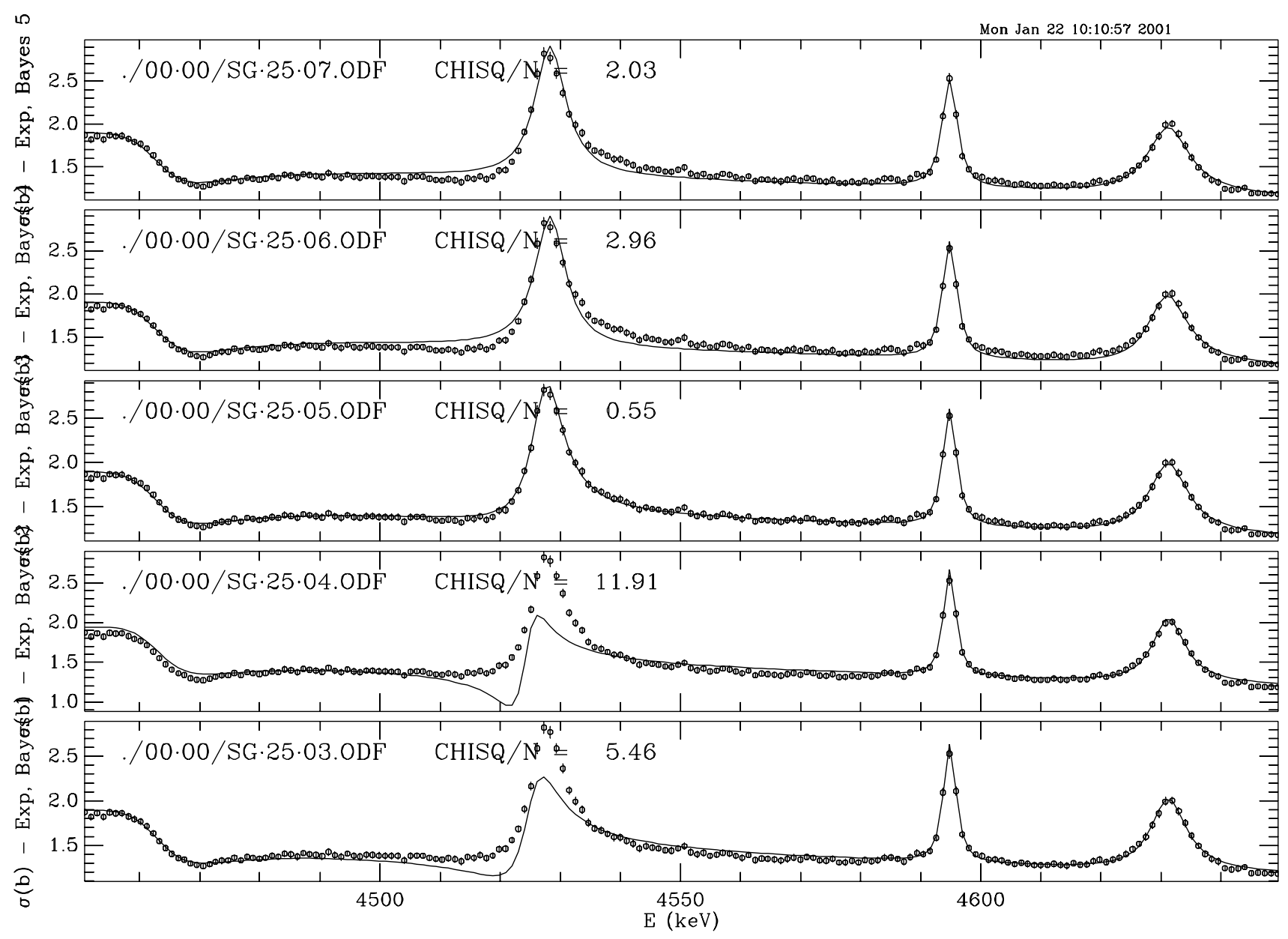

Figure 12B. /home/ros/axp/RSAP/v5/EXAMPLE/12/dosgv25.3thru7

$\begin{array}{ccrrrrr}\text { Resonance } & \text { Group } & \text { CHISQ/NDAT } & \text { Eres }(\mathrm{eV}) & \text { Ggamma } & \text { Gneutron } & \\ 25 & 3 & 5.4591 & 4524764.278 & 2.5000 \mathrm{E}+02 & 5.9355 \mathrm{E}+06 & 7.4464 \mathrm{E}+05 \\ 25 & 4 & 11.9090 & 4525554.599 & 2.5000 \mathrm{E}+02 & 5.4117 \mathrm{E}+06 & 4.7090 \mathrm{E}+05 \\ 25 & 5 & 0.5497 & 4527397.612 & 2.5000 \mathrm{E}+02 & 4.9908 \mathrm{E}+06 & 1.1212 \mathrm{E}+06 \\ 25 & 6 & 2.9556 & 4528284.932 & 2.5000 \mathrm{E}+02 & 4.7568 \mathrm{E}+06 & 1.1009 \mathrm{E}+06 \\ 25 & 7 & 2.0291 & 4528261.389 & 2.5000 \mathrm{E}+02 & 3.6589 \mathrm{E}+06 & 2.2829 \mathrm{E}+06\end{array}$

Eres(eV) Ggamma Gneutron Gfiss1 Gfiss2

\begin{tabular}{|c|c|c|c|c|c|c|c|c|}
\hline 4524764.278 & $2.5000 \mathrm{E}+02$ & $5.9355 E+06$ & $7.4464 \mathrm{E}+05$ & 1 & 01 & 1 & & 200.00 \\
\hline 4525554.599 & $2.5000 E+02$ & $5.4117 \mathrm{E}+06$ & $4.7090 \mathrm{E}+05$ & 1 & 0 & 1 & & 200.00 \\
\hline 4527397.612 & $2.5000 E+02$ & $4.9908 \mathrm{E}+06$ & $1.1212 \mathrm{E}+06$ & 1 & & 1 & & 200.00 \\
\hline 4528284.932 & $2.5000 \mathrm{E}+02$ & $4.7568 E+06$ & $1.1009 \mathrm{E}+06$ & 1 & 0 & 1 & & 200.00 \\
\hline 4528261.389 & $2.5000 E+02$ & $3.6589 E+06$ & $2.2829 E+06$ & 1 & 01 & 1 & & 200.0 \\
\hline
\end{tabular}




\subsection{Resonances treated sequentially.}

Several resonances may be treated sequentially in one RSAP input file. An example RSAP input file for 2 sequential resonances is:

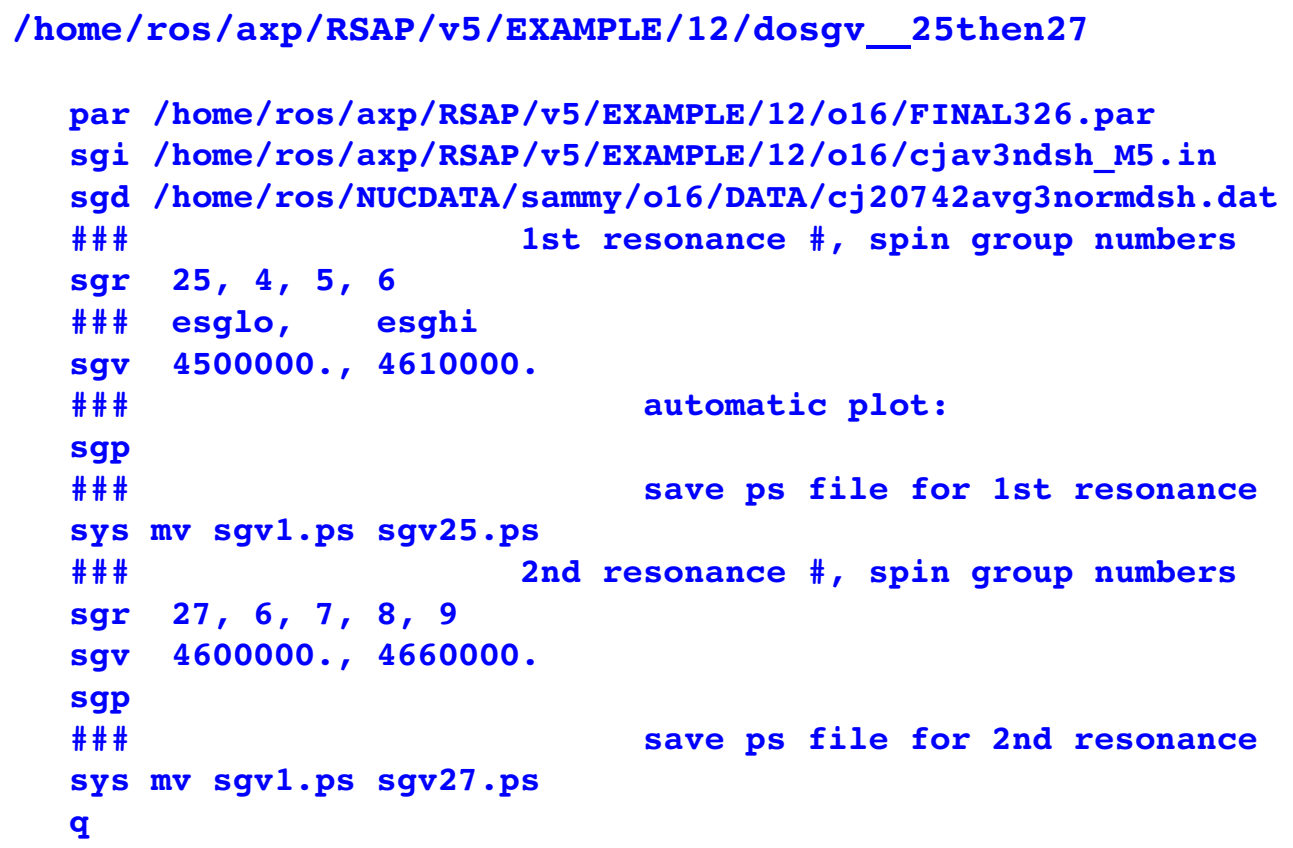

Fit results for the $2^{\text {nd }}$ and subsequent resonances are appended to rsap.chi and rsap.sgvout. The above example file produces a total of 7 SAMMY runs, 3 for resonance 25 and 4 for resonance 27 . Note also that a different energy range is used for each resonance.

\subsection{Two Resonances treated simultaneously.}

Two resonances may be treated simultaneously in one RSAP input file. In this mode RSAP does nested loops over spin groups:

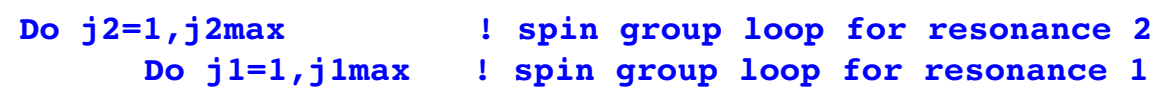

By specifying the maximum of 8 spin groups for each resonance, 64 SAMMY runs could be performed. 
An example RSAP input file for "simultaneous" resonances is:

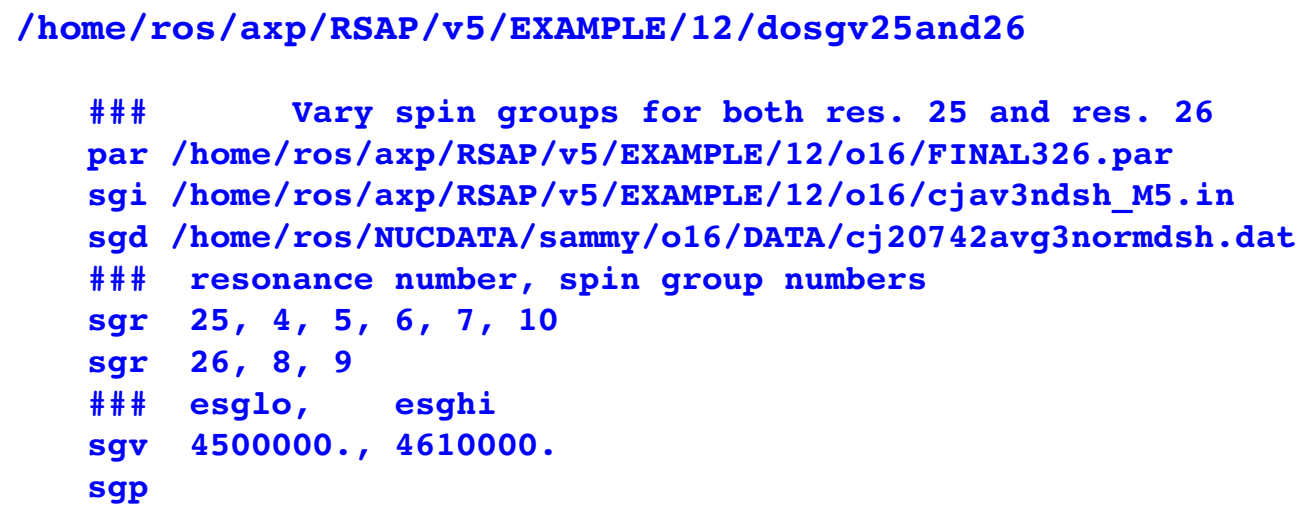

For this example, ODF and final PAR files for each spin group fit are saved in the subdirectories 26_08 and 26_09. The saved files are:

\begin{tabular}{|c|c|}
\hline . /26_08/SG_25_04.PAR & . /26_08/SG_25_04.ODF \\
\hline . /26_08/SG_25_05.PAR & . /26_08/SG_25_05.ODF \\
\hline . /26_08/SG_25_06.PAR & . /26_08/SG_25_06.ODF \\
\hline . /26_08/SG_25_07 .PAR & . /26_08/SG_25_07.ODF \\
\hline . /26_08/SG_25_10.PAR & . /26_08/SG_25_10.ODF \\
\hline . /26_09/SG_25_04.PAR & . /26_09/SG_25_04.ODF \\
\hline . /26_09/SG_25_05.PAR & . /26_09/SG_25_05.ODF \\
\hline . /26_09/SG_25_06.PAR & . /26_09/SG_25_06.ODF \\
\hline . /26_09/SG_25_07.PAR & . /26_09/SG_25_07.ODF \\
\hline . /26_09/SG_25_10.PAR & . /26_09/SG_25_10.ODF \\
\hline
\end{tabular}

The file names are written on the "sgp" plot as shown in Figures 12.C and 12.D.

Fit results are written to files rsap.chi and rsap.sgvout:

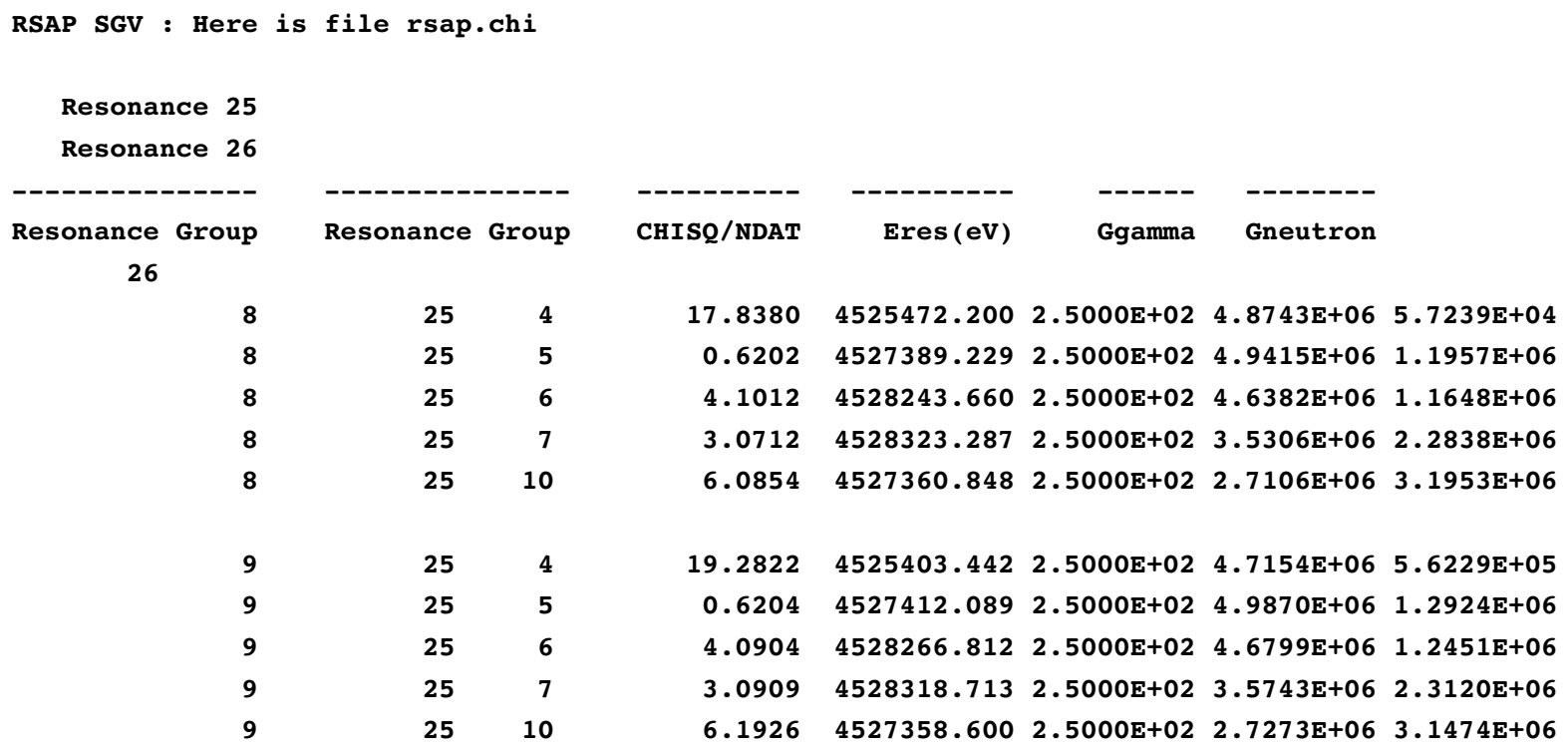




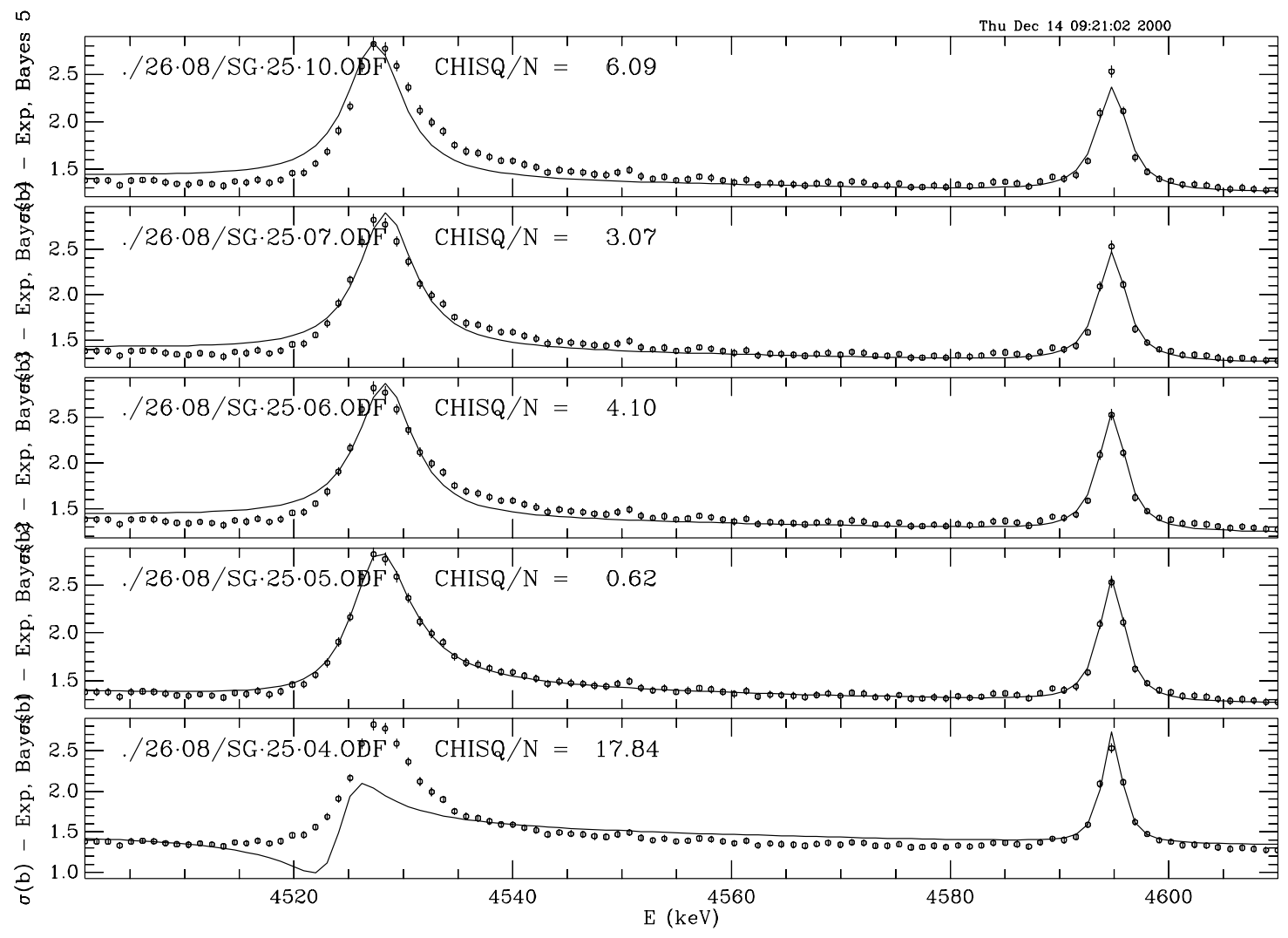

Figure 12C. /home/ros/axp/RSAP/v5/EXAMPLE/12/dosgv25and26

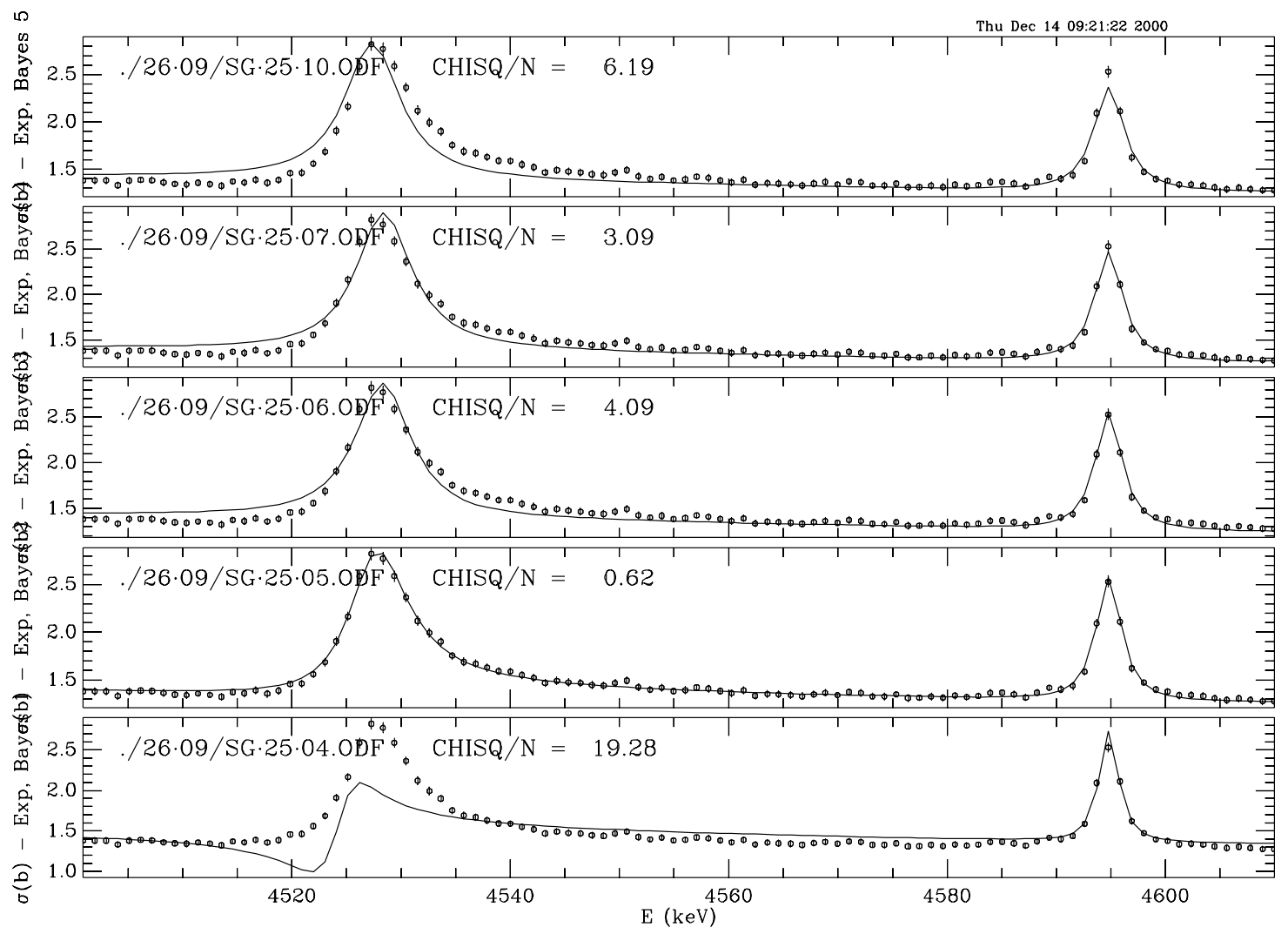

Figure 12D. /home/ros/axp/RSAP/v5/EXAMPLE/12/dosgv25and26 


\section{ACKNOWLEDGEMENTS}

The author acknowledges with pleasure discussions with L. C. Leal, N. M. Larson, H. Derrien, and R. Q. Wright. These and other RSAP users contributed many ideas for enhancement of the code as well as invaluable assistance in the process of finding and correcting code errors.

\section{REFERENCES}

1. N. M. Larson, Oak Ridge National Laboratory Report ORNL/TM-9179/R5, 2000.

2. M. J. LeBrun, G. Furnish, and T. Richardson, The PLPLOT Plotting Library, 1994. http://emma.la.asu.edu/plplot

3. M. A. Mariscotti, Nucl. Inst. Methods 50, 309 (1967). 


\section{APPENDICES}

A. Example Script for SAMMY + RSAP Run

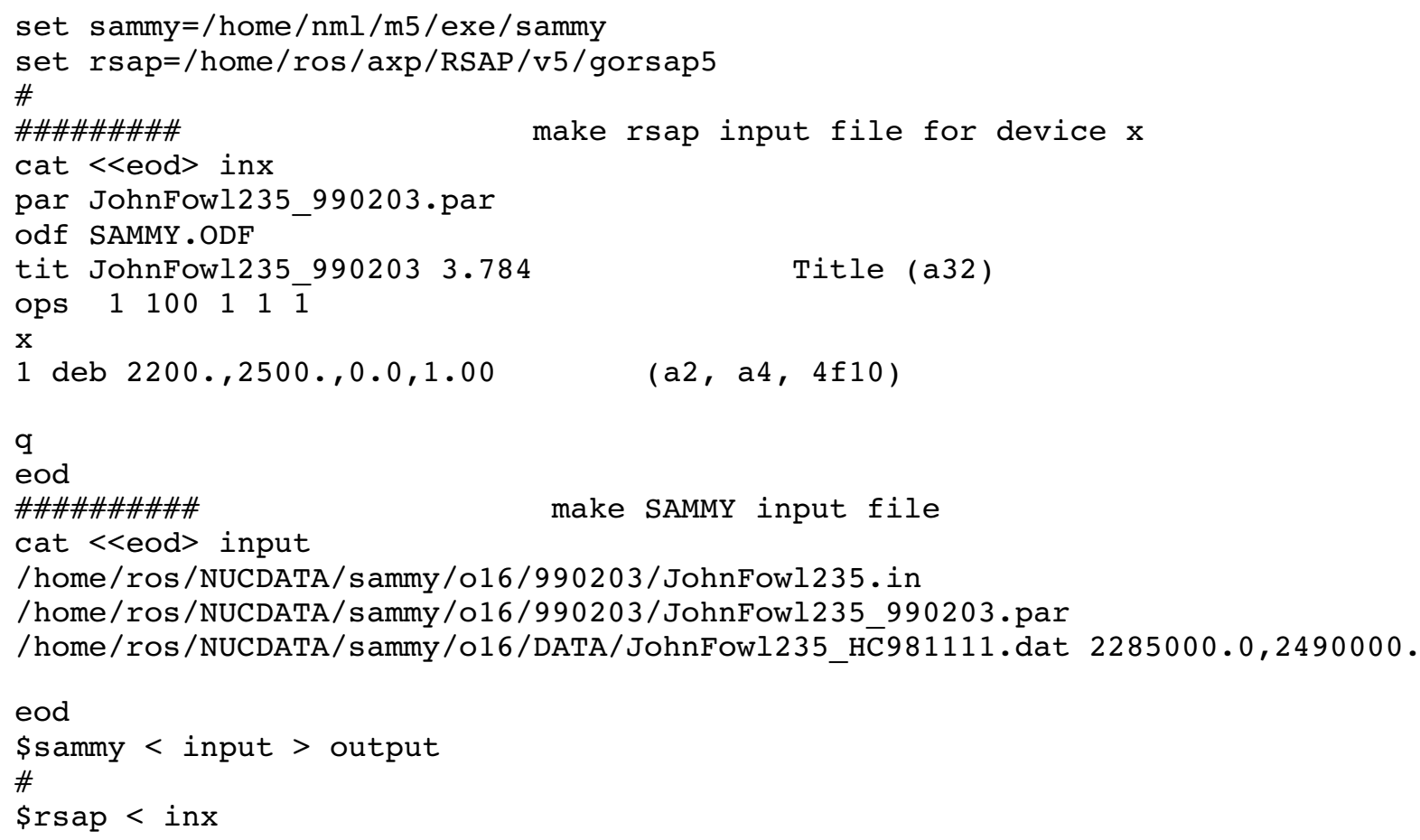

B. Example rsap.ratexpth File

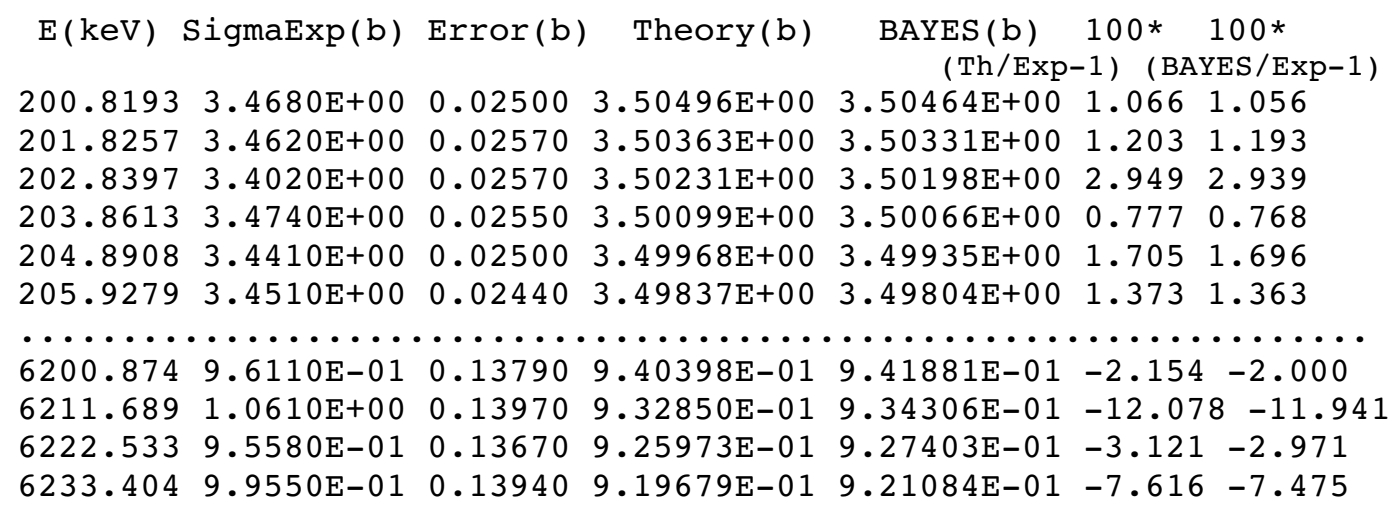




\section{Example rsap.parcom File}

\begin{tabular}{|c|c|c|c|c|c|c|c|c|c|c|}
\hline Res & Grp & $\mathrm{E}(\mathrm{keV})$ & $\mathrm{E} / \mathrm{SAM}$ & Gamc1 & GamC1/SAM & GamC2 & GamC2 / SAM & \multicolumn{2}{|c|}{ Vary } & Eunc. \\
\hline 1 & 1 & -12024.00 & -12021.00 & 9106.20 & 9126.20 & & & 1 & 01 & 10.0 \\
\hline 2 & 1 & -4469.30 & -4469.20 & 5469.30 & 5485.00 & & & 1 & 0 & 1.0 \\
\hline 3 & 3 & 434.30 & 434.30 & 44.17 & 44.40 & & & 1 & 0 & 0.2 \\
\hline 4 & 4 & 1000.28 & 1000.25 & 99.64 & 100.43 & & & 1 & 0 & 0.2 \\
\hline 5 & 3 & 1309.36 & 1309.36 & 43.17 & 43.35 & & & 1 & $\begin{array}{ll}0 & 1\end{array}$ & 0.2 \\
\hline$\cdots$ & $\cdots$ & …... & - . . . & $\cdots \cdots$ & 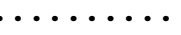 & ・・・・ & & & & \\
\hline 37 & 6 & 6076.13 & 6076.13 & 4.76 & 4.81 & 2.00 & 2.00 & 1 & 0 & 0.2 \\
\hline 38 & 2 & 6087.91 & 6087.90 & 14.53 & 14.57 & 4.51 & 4.51 & 1 & 0 & 0.2 \\
\hline 39 & 7 & 6387.66 & & 9.91 & 10.01 & 35.98 & 36.01 & 0 & 0 & 0.2 \\
\hline 40 & 3 & 10980.19 & 10989.91 & 14338.00 & 14369.00 & & & 1 & 0 & 100.0 \\
\hline 41 & 2 & 18777.06 & 18755.84 & 27453.00 & 27495.00 & & & 1 & 0 & 100.0 \\
\hline 42 & 4 & 16158.63 & 16146.03 & 1926.00 & 1930.90 & & & 1 & 01 & 100.0 \\
\hline
\end{tabular}

RADIUS PARAMETERS FOLLOW
3.77736

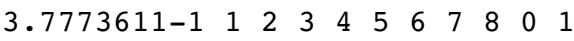
6.49920

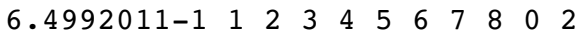

NORMAlization and "constant" background follow $\begin{array}{lllllllllllll}1.0038828 & 0.000 \mathrm{E}+00 & 0.000 \mathrm{E}+00 & 0.000 \mathrm{E}+00 & 0.000 \mathrm{E}+00 & 0.000 \mathrm{E}+00 & 1 & 0 & 0 & 0 & 0 & 0\end{array}$

COVARIANCE MATRIX IS IN BINARY FORM

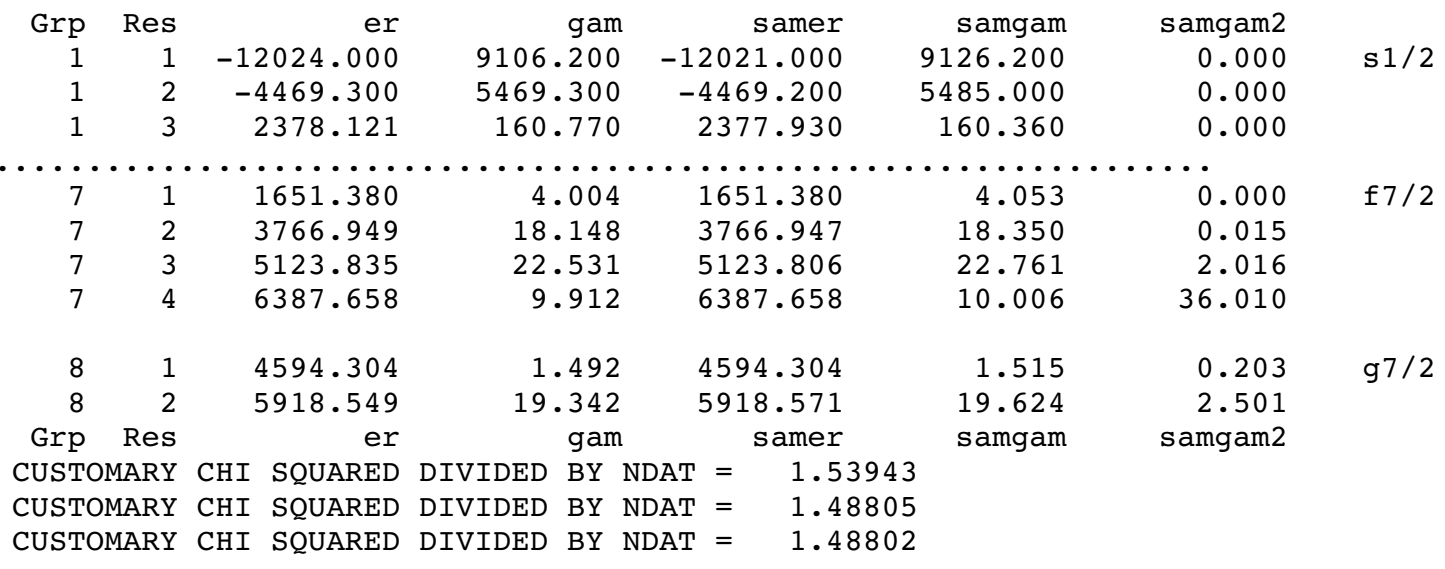




\section{PLPLOT metafiles and plrender}

The discussion herein follows closely the information given in the PLPLOT documentation [2]. A PLPLOT metafile is a binary, device-independent stream of bytes that may be rendered with the PLPLOT utility, plrender.

To render the metafile, rsap.meta, type:

$$
\text { plrender [options] rsap.meta }
$$

where

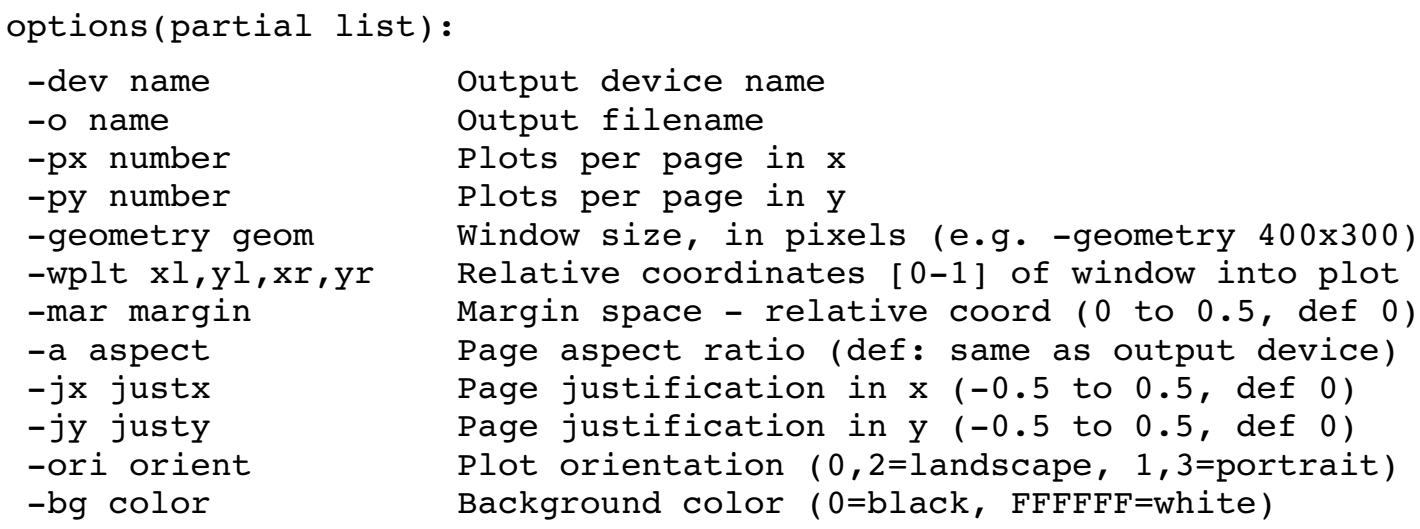

All parameters must be white-space delimited. Not all options valid with all drivers.

A complete list of options may be obtained by typing "plrender $-\mathrm{h}$ ".

For example, to make a color postscript file, rsap_port, in portrait orientation on a white background:

plrender -dev psc -bg FFFFFF -o rsap_port -ori 3 rsap.meta 


\section{INTERNAL DISTRIBUTION}

$\begin{aligned} 1 . & \text { H. Derrien } & 17 . & \text { N. M. Larson } \\ 2 . & \text { F. C. Difilippo } & 18 . & \text { L. C. Leal } \\ 3 . & \text { M. E. Dunn } & 19 . & \text { C. V. Parks } \\ 4 . & \text { C. Y. Fu } & 20 . & \text { S. Raman } \\ 5 . & \text { N. M. Greene } & 21-24 . & \text { R. O. Sayer } \\ 6 . & \text { K. Guber } & 25 . & \text { M. S. Smith } \\ 7 . & \text { F. B. Guimaraes } & 26 . & \text { T. Valentine } \\ 8 . & \text { J. A. Harvey } & 27 . & \text { K. N. Volev } \\ 9 . & \text { D. M. Hetrick } & 28 . & \text { R. M. Westfall } \\ 10 . & \text { C. M. Hopper } & 29 . & \text { J. E. White } \\ 11 . & \text { H. T. Hunter } & 30 . & \text { R. R. Winters } \\ 12 . & \text { D. T. Ingersoll } & 31 . & \text { R. Q. Wright } \\ 13 . & \text { B. L. Kirk } & 32-35 . & \text { RSICC } \\ 14 . & \text { P. E. Koehler } & 36-37 . & \text { Laboratory Records (OSTI) } \\ 15 . & \text { M. A. Kuliasha } & 38 . & \text { Laboratory Records } \\ 16 . & \text { D. C. Larson } & 39 . & \text { Central Research Library }\end{aligned}$

\section{EXTERNAL DISTRIBUTION}

40. S. M. Austin, NSCL/Cyclotron Lab, Michigan State University, East Lansing, MI 48824

41. C. Bastien, Central Bureau for Nuclear Measurements, Steenweg op Retie, 2240 Geel, Belgium

42. H. Beer, Forschungszentrum Karlsruhe, IK, BAV 425, Postfach 3640, D-76021, Karlsruhe, Germany

43. R. Block, Rensselaer Polytechnic Institute, Troy, NY 12180-3590

44. O. Bouland, DER/SPRC/LEPH, Batiment 230, Centre d=Etudes de CADARACHE, 13108, Saint Paul-lez-Durance, France

45. A. Brusegan, Central Bureau for Nuclear Measurements, Steenweg op Retie, 2240 Geel, Belgium

46. David Buchan, Ontario Hydro P41 E1 Pickering Nuclear Generating Station, 1675 Montgomery Park Rd., Pickering Ontario, CANADA L1V 2R5

47. J. Burke, Gaerttner LINAC Laboratory, Rensselaer Polytechnic Institute, Department of Environmental and Energy Engineering, Troy, NY 12180-3590

48. D. E. Carlson, U.S. Nuclear Regulatory Commission, Reactor and Plant System Branch, Division of System Research, Office of Nuclear Regulatory Research, MS T-10 G6, RM T-10, 17, Washington, DC 20555-0001

49. R. F. Carlton, Middle Tennessee State University, Department of Chemistry and Physics, Murfreesboro, TN 37132

50. E. Caro, Lockheed Martin Corporation, P.O. Box 1072, Schenectady, NY 12301-1072

51. M. B. Chadwick, Los Alamos National Laboratory, MS B243 T-16, Los Alamos, NM 87545

52. J. Chang, Korea Atomic Energy Research Inst., Nuclear Data Evaluation Lab., P. O. Box 105, Yusung, Taejon 305-600, Korea

53. Y. Danon, Gaerttner LINAC Laboratory, Rensselaer Polytechnic Institute, Department of Environmental and Energy Engineering, Troy, NY 12180-3590

54. C. Dunford, Brookhaven National Laboratory, Bldg 197D, National Nuclear Data Center, Upton, NY 11973

55. P. Finck, Argonne National Laboratory, Reactor Analysis Division, Bldg 208, Argonne, IL 60439

56. C. M. Frankle, Los Alamos National Laboratory, NIS-6MS J562, Los Alamos, NM 87545

57. W. Furman, Frank Laboratory of Neutron Physics, JINR, Dubna, Russia

58. S. Ganesan, Head, Nuclear Data Section, Indira Gandhi Centre for Atomic Research, Kalpakkam 603 102, Tamilnadu, India 
59. V. Gavron, Los Alamos National Laboratory, P.O. Box 1663 NIS-5 MS-E540, Los Alamos, NM 87545

60. Thomas B. Gosnell, Lawrence Livermore National Laboratory, 7000 East Avenue L-175, Livermore, CA 94550

61. F. Gunsing, Centre D'Etudes De Saclay, F-Saclay - 91191, Gif-sur-Yvette Cedex, France

62. G. M. Hale, Los Alamos National Laboratory, T-2, MS B243, Los Alamos, NM 87545

63. A. Hasagawa, Nuclear Data Center Japan Atomic Energy Research Institute, Tokai-mura, Naka-gun, lbaraki-ken 319-11, Japan

64. R. N. Hwang, Argonne National Laboratory, Reactor Analysis Division, Bldg 208, Argonne, IL 60439

65. R. P. Jacqmin, DER/SPRC/LEPH, Batiment 230, Centre d'Etudes de CADARACHE, 13408, Saint Paul-lez-Durance, France

66. M. Jaeger, Inst. F. Strahlenphysik, Allmandring 3, Stuttgart D-70569, Germany

67. N. Janeva, Bulgarian Academy of Sciences, 72, Boul, Tzarigradsko shosse, Sofia 1784, Bulgaria

68. H. C. Johnson, U.S. Department of Energy, EM-21 Forrestal, 1000 Independence Ave. SW, Washington, DC 20585

69. F. Kappeler, Forschungszentrum Karlsruhe, IK, BAV 425, Postfach 3640, D-76021, Karlsruhe, Germany

70. Lambros Lois, U.S. Nuclear Regulatory Commission, 08 E23, 11555 Rockville Pike, Rockville, MD 20852-2746

71. G. Leinweber, Gaerttner LINAC Laboratory, Rensselaer Polytechnic Institute, Dept. of Environmental and Energy Engineering, Troy, NY 12180-3590

72. R. Little, Los Alamos National Laboratory, X-TM, MS B226, Los Alamos, NM 87545

73. M. Lubert, Gaerttner LINAC Laboratory, Rensselaer Polytechnic Institute, Department of Environmental and Energy Engineering, Troy, NY 12180-3590

74. C. Lubitz, Knolls Atomic Power Laboratory, P. O. Box 1072, Schenectady, NY 12301

75. R. E. MacFarlane, Los Alamos National Laboratory, T-2, MS B243, Los Alamos, NM 87545

76. C. Mounier, CEN Saclay, DMT/SERMA/LENR, , 91191 Gif Sur Yvette Cedex, France

77. D. Muir, IAEA Nuclear Data Section, Wagramerstr. 5, P. O. Box 100, A-1400, Wien, Austria

78. C. Nordborg, OECDNEA, Le Seine St-Germain 12, Boulevard Iles, 92130, Issy-les-Moulineaux, France

79. A. Nouri, OECD/NEA Data Bank, Le Seine Saint Germain 12 Bd des Iles, 92130 Issy-les-Moulineaux, France

80. S. Y. Oh, Nuclear Data Evaluation Lab., Korea Atomic Energy Research Institute, P. O. Box 105, Yusung, Taejon, 305-600 Korea

81. C. Raepsaet, CEN Saclay, DMT/SERMA/LEPP, 91191, Gif Sur Yvette Cedex, France

83. M. Salvatores, DRN/P, Batiment 707, C. E. CADARACHE, 13108, Saint Paul-lez-Durance, France

84. E. Sartori, OECDNEA, Le Seine St-Germain 12, Boulevard Iles, 92130, Issy-les-Moulineaux, France

85. R. Shelley, Central Bureau for Nuclear Measurements, Steenweg op Retie, 2240 Geel, Belgium

86. P. Siegler, Central Bureau for Nuclear Measurements, Steenweg op Retie, 2240 Geel, Belgium

87. K. Shibata, Japan Atomic Energy Research Institute, Nuclear Data Center, Tokai-mura Naka-gun, Ibaraki-ken 319-11, Japan

88. Mihaela Sin, Bucharest University Nuclear Physics Department, P.O. Box MG-11, RO-76900 Bucharest-Magurele, Romania

89. D. L. Smith, Argonne National Laboratory, TD-360-L106, Argonne, IL 60544

90. H. Takano, Japan Atomic Energy Research Institute, Nuclear Data Center, Tokai-mura, Naka-gun, Ibaraki-ken 319-11, Japan

91. C. Wagemans, Central Bureau for Nuclear Measurements, Steenweg op Retie, 2240 Geel, Belgium

92. J. J. Wagschal, Racah Institute of Physics, The Hebrew University of Jerusalem, 91904 Jerusalem, Israel

93. H. Weigmann, Central Bureau for Nuclear Measurements, Steenweg op Retie, 2240 Geel, Belgium

94. J. P. Weinman, Lockheed Martin Corporation, P.O. Box 1072, Schenectady, NY 12301-1072

95. C. Werner, Rensselaer Polytechnic Institute, Residence Hall, 1999 Burdette Ave, Troy, NY 12180-3711

96. R. M. White, Lawrence Livermore National Laboratory, P. O. Box 808, Livermore, CA 94550

97. K. Yoo, Korea Atomic Energy Research Inst., Nuclear Data Evaluation Lab., P. O. Box 105, Yusung, Taejon 305-600, Korea 